\title{
Kinetics of the thermal decomposition of tetramethylsilane behind the reflected shock waves between 1058 and $1194 \mathrm{~K}$
}

\author{
A PARANDAMAN and B RAJAKUMAR* \\ Department of Chemistry, Indian Institute of Technology Madras, Chennai 600 036, India \\ e-mail: rajakumar@iitm.ac.in
}

MS received 16 September 2015; revised 31 December 2015; accepted 4 January 2016

\begin{abstract}
Thermal decomposition of tetramethylsilane (TMS) diluted in argon was studied behind the reflected shock waves in a single pulse shock tube (SPST) in the temperature range of 1058-1194 K. The major products formed in the decomposition are methane $\left(\mathrm{CH}_{4}\right)$ and ethylene $\left(\mathrm{C}_{2} \mathrm{H}_{4}\right)$; whereas ethane and propylene were detected in lower concentrations. The decomposition of TMS seems to be initiated via Si-C bond scission by forming methyl radicals $\left(\mathrm{CH}_{3}\right)$ and trimethylsilyl radicals $\left(\left(\mathrm{CH}_{3}\right)_{3} \mathrm{Si}\right)$. The total rate coefficients obtained for the decomposition of TMS were fit to Arrhenius equation in two different temperature regions $1058-1130 \mathrm{~K}$ and $1130-1194 \mathrm{~K}$. The temperature dependent rate coefficients obtained are $\mathrm{k}_{\text {total }}(1058-1130 \mathrm{~K})$ $=(4.61 \pm 0.70) \times 10^{18} \exp \left(-\left(79.9 \mathrm{kcal} \mathrm{mol}^{-1} \pm 3.5\right) / \mathrm{RT}\right) \mathrm{s}^{-1}, \mathrm{k}_{\text {total }}(1130-1194 \mathrm{~K})=(1.33 \pm 0.19) \times 10^{6} \exp$ $\left(-\left(15.3 \mathrm{kcal} \mathrm{mol}^{-1} \pm 3.5\right) / \mathrm{RT}\right) \mathrm{s}^{-1}$. The rate coefficient for the formation of $\mathrm{CH}_{4}$ is obtained to be $k_{\text {methane }}$ $(1058-1194 \mathrm{~K})=(4.36 \pm 1.23) \times 10^{14} \exp \left(-\left(61.9 \mathrm{kcal} \mathrm{mol}^{-1} \pm 4.9\right) / \mathrm{RT}\right) \mathrm{s}^{-1}$. A kinetic scheme containing 21 species and 38 elementary reactions was proposed and simulations were carried out to explain the formation of all the products in the decomposition of tetramethylsilane.
\end{abstract}

Keywords. tetramethylsilane; single pulse shock tube; decomposition; shock wave; simulation.

\section{Introduction}

Tetramethylsilane (TMS) is the simplest carbosilane, broadly used in semiconductor industry as a precursor for preparation of silicon carbide (SiC) through chemical vapor deposition (CVD) technique. ${ }^{1,2}$ Silicon carbide $(\mathrm{SiC})$ is used in various applications because of its important properties such as high heat resistance, high thermal conductivity and to withstand high voltage. ${ }^{3}$ It is a well-known promising substrate material for power electronic devices and light emitting devices (LED). ${ }^{4}$ Good quality $\mathrm{SiC}$ films can be grown on $\mathrm{Si}$ substrates by pyrolyzing single organosilane precursors, which contain bonds between $\mathrm{Si}$ and $\mathrm{C}$ atoms, such as methylsilane $\left(\mathrm{CH}_{3} \mathrm{SiH}_{3}\right)$, tetramethylsilane $\left(\left(\mathrm{CH}_{3}\right)_{4} \mathrm{Si}\right)$, methyltrichlorosilane $\left(\mathrm{CH}_{3} \mathrm{SiCl}_{3}\right){ }^{5-7}$ Among them, TMS has more advantages as a precursor. It is considered as a safe, non-explosive and non-corrosive precursor material that can be easily handled in the experiments. ${ }^{8}$

As TMS is the source to provide Si, our initial focus would be on the resultant products from TMS formed via $\mathrm{Si}-\mathrm{C}$ bond breaking reactions. Seo et al.,${ }^{9}$ produced 3C-SiC(111) films on Si substrates from TMS, employing a rapid thermal CVD technique above $1000^{\circ} \mathrm{C}$. They reported that TMS decomposed into $\mathrm{H}$ and $\mathrm{Si}$ atoms

*For correspondence and hydrocarbon gases such as $\mathrm{CH}_{4}, \mathrm{C}_{2} \mathrm{H}_{2}$, and $\mathrm{C}_{2} \mathrm{H}_{4}$ at high temperatures. Herlin et al. ${ }^{10}{ }^{10}$ studied the growth mechanism of $\mathrm{SiC}$ on a graphite susceptor in a lowpressure cold wall reactor. They found that dissociation of TMS releases $\mathrm{H}$ atoms, various Si-containing species and hydrocarbons. In all these experiments no consistent conclusions about the products from TMS decomposition were made. The detailed analysis on products and clear understanding of mechanism is the main focus of the present study. Various precursors such as TMS, diethylsilane and tripropylsilane are commonly used in the preparation of SiCvia CVD. Previous investigations by Avigal and Schieber ${ }^{11}$ reported that, $\mathrm{SiC}$ was obtained from TMS either in an inert $(\mathrm{He})$ atmosphere or reducing $\left(\mathrm{H}_{2}\right)$ atmosphere in the temperatures between 700 and $1400^{\circ} \mathrm{C}$. Several experimental studies reported that TMS was used for conventional CVD experiments $^{12,13}$ to produce solid materials of high efficiency and high purity. In the process of CVD at high temperature with TMS, the subject of gas phase contribution to the overall process cannot be neglected.

The spontaneous flammability of certain alkylsilanes suggest that metal - carbon bonds are more susceptible to oxidation than carbon - hydrogen or carbon carbon bonds. Schalla et al. ${ }^{14}$ studied the temperature required for the rapid oxidation or explosion of alkylsilanes (including TMS) air mixtures at one atmospheric 
pressure and they have reported the explosion limits of a series of alkylsilanes. $\mathrm{SiC}$ was also synthesized by injecting mixture of carrier gas $\left(\mathrm{H}_{2}, \mathrm{He}, \mathrm{N}_{2}\right.$ and $\left.\mathrm{C}_{2} \mathrm{H}_{4}\right)$ and TMS into hot burned gas downstream of a fuel rich hydrocarbon oxygen flame. ${ }^{15}$ Cullis et al. ${ }^{16}$ studied the possibility of silicon containing compounds including TMS as anti-knock additives in engines and they have concluded that none of these silicon compounds are viable anti-knock additives in fuels.

TMS has simple carbosilane structure and is used as a model monomer for studying the reactivity of silylmethyl groups in plasma polymerization reactions. ${ }^{17}$ The thermal decomposition studies on TMS were conducted by Helm and Mack ${ }^{18}$ in a static reactor and they have reported that the reaction was unimolecular and homogeneous at pressures above 100 Torr in the temperature range of $932-993 \mathrm{~K}$. The thermal decomposition studies on TMS were also carried out by Clifford et al. ${ }^{19}$ in a linear flow system in the temperature range of 810-980 K, using gas chromatography for the detection of reactant and products. They have reported the first order rate coefficient for the formation of methane to be $k=2.0 \times 10^{14} \exp \left(-67.9 \mathrm{kcal} \mathrm{mol}^{-1} / \mathrm{RT}\right) \mathrm{s}^{-1}$. The decomposition of TMS was also studied by Baldwin et al. ${ }^{20}$ in a pulsed stirred-flow system between 800 and $1055 \mathrm{~K}$ using GLC-Mass spectrometry as a detection system. They have reported two sets of rate coefficients for the formation of $\mathrm{CH}_{4}$ from the decomposition of TMS. The first order rate coefficient for the formation of $\mathrm{CH}_{4}$ in the temperature range of $840-950 \mathrm{~K}$ was reported to be $k=1.58 \times 10^{11} \exp \left(-57.4 \mathrm{kcal} \mathrm{mol}^{-1}\right.$ /RT) $\mathrm{s}^{-1}$, and for temperature range of $955-1055 \mathrm{~K}$, the rate coefficient reported was $k=3.98 \times 10^{17} \mathrm{exp}$ $\left(-85.2 \mathrm{kcal} \mathrm{mol}^{-1} / \mathrm{RT}\right) \mathrm{s}^{-1}$, where the activation energies are given in $\mathrm{kcal} \mathrm{mol}^{-1}$. Taylor et al., ${ }^{21}$ studied the pyrolysis of tetramethyl derivatives of silicon, germanium and tin using a wall less reactor under both homogeneous and heterogeneous (surface) conditions.
They have reported the rate coefficient for the pyrolysis of TMS in homogeneous conditions to be $k=$ $1.29 \times 10^{14} \exp \left(-72.0 \mathrm{kcal} \mathrm{mol}^{-1} / \mathrm{RT}\right) \mathrm{s}^{-1}$ and in surface conditions it was reported to be $k=3.16 \times 10^{12} \exp$ $\left(-61.0 \mathrm{kcal} \mathrm{mol}^{-1} / \mathrm{RT}\right) \mathrm{s}^{-1}$. Although the decomposition of TMS were studied earlier in a wide temperature range of $800-1055 \mathrm{~K}$ by various groups, complete mechanistic studies were not reported so far, to the best of our knowledge.

In the present investigation, we report the complete thermal decomposition of TMS in the temperature range of 1058-1194 K. A most plausible mechanism for the decomposition is proposed and simulated. The decomposition pathways and the mechanistic approach are discussed in this paper. In the present study, the solid products and their growth were not monitored. However, formation of lower hydrocarbon products and their gas phase contribution to the overall reaction were focused. Silicon containing products were not observed from post shock mixture analysis. If TMS was extensively used as a precursor for preparation of $\mathrm{SiC}$, lower hydrocarbons along with solid $\mathrm{SiC}$ will be formed at higher temperatures. Si-C bond breaking is the most important channel and the primary step in the pyrolysis of TMS because $\mathrm{Si}-\mathrm{C}$ bond energy ${ }^{20}$ is $85 \mathrm{kcal} \mathrm{mol}^{-1}$ which is lower than $\mathrm{C}-\mathrm{H}$ bond dissociation ${ }^{22}$ energy $\left(99.2 \mathrm{kcal} \mathrm{mol}^{-1}\right)$.

\section{Experimental}

The thermal decomposition of TMS was studied behind the reflected shock waves in a single pulse shock tube (SPST).A schematic diagram of the SPST used in this study is given in figure 1. A $50.8 \mathrm{~mm}$ i.d. SPST consisting of a $3440 \mathrm{~mm}$ long driven section and $1290 \mathrm{~mm}$ length driver section was used in the present investigation. The driver section was separated from the driven section by an aluminum diaphragm.

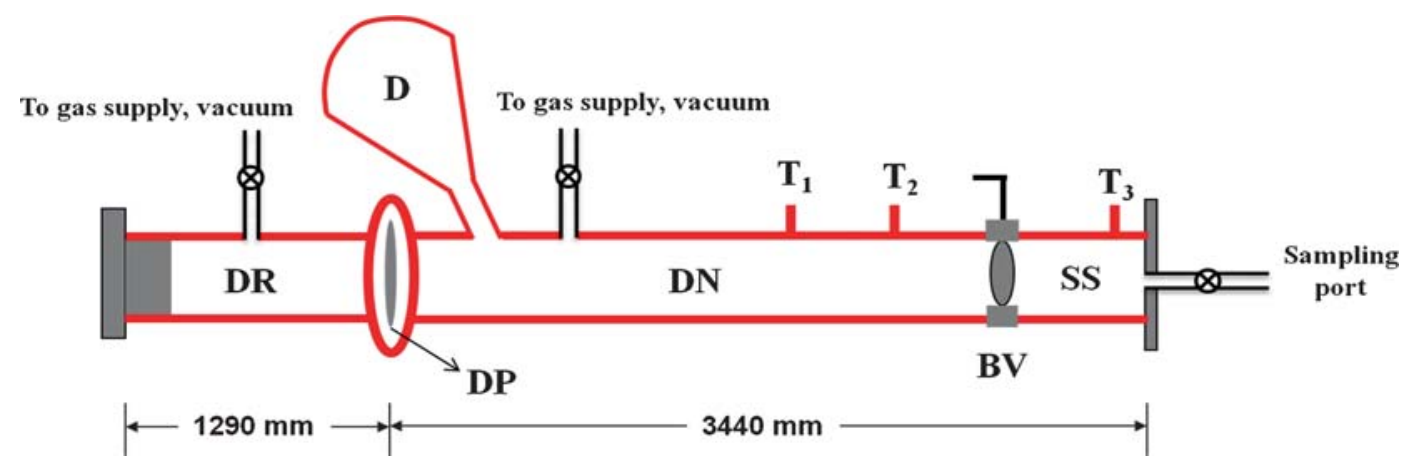

Figure 1. Schematic diagram of the single pulse shock tube used in the present study. DRdriver section, DN-driven section, SS-sample section, BV-ball valve, DP-diaphragm, $\mathrm{T}_{1}, \mathrm{~T}_{2}$ and $\mathrm{T}_{3}$-pressure transducers, D- dump tank. 
A confined reaction zone was created towards the end of the shock tube by incorporating a ball valve. This is to ensure that all the test molecules are exposed to the reflected shock wave. The success of shock tube technique depends on exposing a reaction mixture to a single high temperature pulse, in which the reactants are allowed to remain at reaction conditions (constant temperature) for a closely controlled period of time, i.e., reaction time, followed by rapid cooling through the action of strong rarefaction wave. The cooling rate must be sufficiently high to effectively freeze the reaction. The problem of a variable dwell time may be substantially reduced by introducing a small test section in the shock tube. The lengths of the driver and driven sections were chosen in such a way that the expansion fan cools the heated sample before the reflected wave meets the contact surface. The location of the ball valve ( $550 \mathrm{~mm}$ from the end of the driven section) was chosen to ensure that the compressed test gas occupies a region around the pressure transducer. Hence, the dwell time measured from the pressure trace is very close to the reaction time, i.e., the time for which the molecules were kept at the temperature behind the reflected wave, $T_{5}$. The smaller test section created using a ball valve will facilitate fixing the dwell time. ${ }^{23-25}$ In fact, the progress of the shock wave will be influenced if, there is a sudden and significantly larger change in the specific heat ratios across the ball valve. The concentration of the sample is chosen in such a way that the specific heat ratio remains almost constant after dilution with the same buffer gas, argon. If the entire driven section is filled with the test sample, the sample beyond the contact surface would not get heated by the reflected shock wave as it is already got attenuated by the expansion fan at the contact surface. Therefore, a small test section was made to carry out these experiments. In fact, this method was used extensively by various groups. ${ }^{24-26}$ Three pressure transducers (PCB 113A22) were mounted towards the end of the driven section. The mounted pressure transducers were used to measure the shock velocity and thereby to calculate both the primary and reflected shock temperatures. The pressure transducer, which is mounted closest to the end flange, was used to record the pressure trace and the reaction time.

A typical pressure trace recorded using the pressure transducer mounted near the end flange is shown in figure 2 . The reaction time of each experiment was measured from the pressure trace. Shock velocities were calculated using the time taken for the incident shock wave to travel between successive pressure transducers. The pressures behind the reflected shock waves

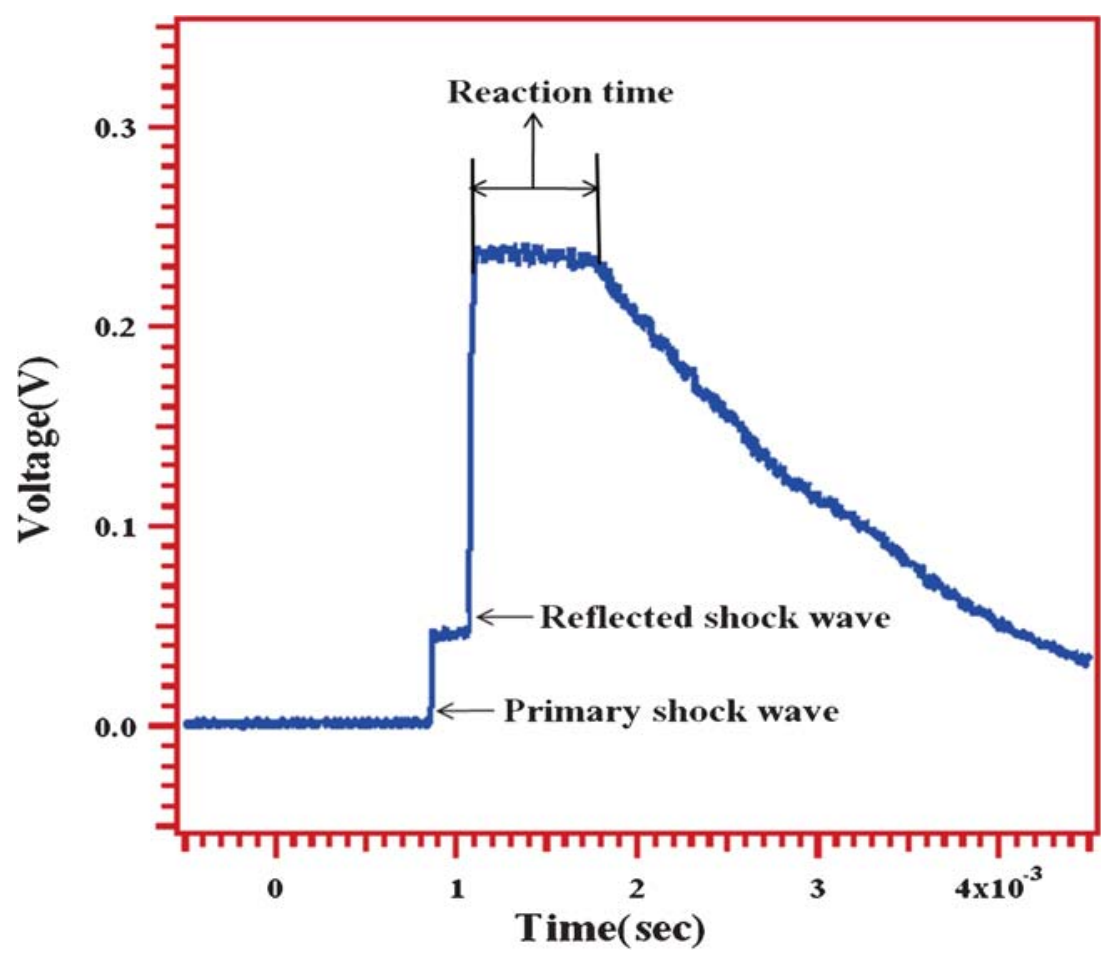

Figure 2. A typical pressure trace recorded by an oscilloscope showing the complete pressure profile in an experiment. The arrival of primary and reflected shock waves and reaction time are indicated on the pressure trace. 
were calculated using the pressure jumps recorded in the pressure trace.

As described by many researchers earlier, the reflected shock temperature $\left(\mathrm{T}_{5}\right)$ computed by conventional Rankine-Hugoniot $(\mathrm{R}-\mathrm{H})$ relations ${ }^{27}$ is given below. They suffer from real gas effects and boundary layer problems. ${ }^{28-31}$

$$
\frac{T_{5}}{T_{1}}=\frac{\left\{2\left(\gamma_{1}-1\right) M_{1}^{2}+\left(3-\gamma_{1}\right)\right\}\left\{\left(3 \gamma_{1}-1\right) M_{1}^{2}-2\left(\gamma_{1}-1\right)\right\}}{\left(\gamma_{1}+1\right)^{2} M_{1}^{2}}
$$

Where $T_{1}$ is the room temperature, $T_{5}$ is the reflected shock temperature, $\gamma_{1}$ is the specific heat ratio of the test gas and $\mathrm{M}_{1}$ is the shock Mach number. To overcome the effects like real gas and boundary layer effects, chemists have developed the chemical thermometry method $^{32-35}$ to get the accurate reflected shock temperatures. In kinetics, as the accuracy in measuring the temperature is very important, the chemical thermometric method was used in our investigations. In the present investigation, the reflected shock temperatures were determined by the extent of reverse DielsAlder decomposition of cyclohexeneto 1,3-butadiene and ethylene, which is added in the reaction mixture to serve as chemical thermometer.

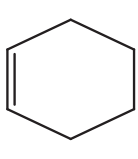

cyclohexene

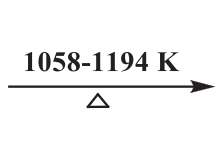

1,3-butadiene

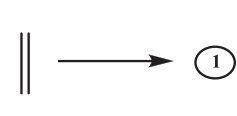

ethylene
Recently, there was a revisit on the rate coefficient for the decomposition of the cyclohexene by Ronald Hanson's group for the reaction of cyclohexene $\rightarrow$ ethylene $+1,3$-butadiene. ${ }^{36}$ We have used this rate coefficient $\mathrm{k}=4.84 \times 10^{14} \exp \left(-63.39 \mathrm{kcal} \mathrm{mol}^{-1} / \mathrm{RT}\right) \mathrm{s}^{-1}$, (where $\mathrm{R}$ is expressed in the units of $\mathrm{kcal} \mathrm{K}^{-1} \mathrm{~mol}^{-1}$ ) in the calculation of the reflected shock temperature. The accuracy of the temperatures estimated using the internal standard depends on the error associated with the reported rate coefficient for the decomposition of the internal standard. The reflected shock temperatures were calculated from the relation

$$
T=-\left(E_{a} / R\right) /\left[\ln \left\{-\frac{1}{A t} \ln (1-\chi)\right\}\right] .
$$

where ' $\mathrm{t}$ ' is the reaction time, ' $\mathrm{A}$ ' and ' $\mathrm{E}_{\mathrm{a}}$ ' are the preexponential factor and activation energy of the reaction, and $\chi$ is the extent of reaction defined by $\chi=$ [product $]_{\mathrm{t}} /\left([\text { reactant }]_{\mathrm{t}}+[\text { product }]_{\mathrm{t}}\right)$.

Internal standard (ISD) method removes all the natural uncertainties in the physical properties. The introduction of the internal standard eliminates the uncertainty in the measurement of the temperature, because both the internal standard and reactant molecule experience the same reaction conditions. Therefore, these temperatures were used in the present investigation.

The driver and driven sections of the shock tube were separated by a pre-scored aluminum diaphragm of desired thickness. Before the experiment both the driver and driven sections were pumped down to approximately $1 \times 10^{-6}$ Torr using a diffusion pump, after making the shock tube rich in argon environment. This procedure was repeated for two to three times before each experiment is carried out to ensure that no oxygen is left in the shock tube. 10 Torr of TMS and 10 Torr of cyclohexene were added into the sample section of the shock tube using a capacitance manometer (MKS 626B) and the mixture was diluted with argon till desired pressure (200-550 Torr) is attained. Argon alone was filled into the section between the sample compartment and the diaphragm. The pressure in the sample compartment was kept lower than the section between the sample compartment and aluminum diaphragm, by about 10 Torr to make sure the sample does not get diffused backwards, when the ball valve is opened before the experiment is carried out. The $\mathrm{P}_{1}$ value of each experiment and initial concentrations of both the reactant and the internal standard are given in table 1 . When $\mathrm{P}_{1}$ is low, higher Mach number could be expected and a higher $\mathrm{T}_{5}$ will be obtained. However, this generalized observation depends on other factors as well. $\mathrm{P}_{4}$ plays a very significant role in achieving a targeted $T_{5}$, which in turn depends on the thickness of the diaphragm and the depth to which it was scored. Therefore, $\mathrm{P}_{1}$ and $\mathrm{P}_{4}$ plays a combined role on $\mathrm{T}_{5}$. In the present experiment, the diaphragms used were scored to a depth of $20 \%, 25 \%$ and $30 \%$ of their thickness. As it is a combination of all these factors, it is difficult to talk about the attained $\mathrm{T}_{5}$ by looking at $\mathrm{P}_{1}$ alone. There will not be any significant or measurable changes in the reflected shock temperatures during the course of reaction, as the concentrations of the test samples are very less. The shock waves were generated by rupturing the diaphragm via filling the driver section with helium to the threshold pressure of the pre-scored aluminum diaphragm. After finishing the experiment, the post shocked mixtures were allowed to mix thoroughly for about $30 \mathrm{~min}$. The postshock mixtures were quantitatively analysed by gas chromatography (Agilent $6890 \mathrm{~N}$ ). The samples were withdrawn from the shock tube and a constant volume of $0.5 \mathrm{~mL}$ samples were injected through an online gas sampling valve into the gas chromatograph equipped with a Flame Ionization Detector (FID). A Porapak-Q column was used for the analysis and oven temperature was programmed from $75^{\circ} \mathrm{C}$ to $180^{\circ} \mathrm{C}$. Nitrogen was 
Table 1. Experimental conditions and distribution of normalized concentrations of reactant and reaction products in the decomposition of TMS.

\begin{tabular}{|c|c|c|c|c|c|c|c|c|c|c|c|}
\hline $\begin{array}{l}\text { Sl. } \\
\text { No }\end{array}$ & $\begin{array}{c}\text { Pressure } \\
\mathrm{P}_{1} \\
\text { (Torr) }\end{array}$ & $\begin{array}{c}\text { Initial } \\
\text { concentration } \\
\text { of TMS }\end{array}$ & $\begin{array}{c}\text { Initial } \\
\text { concentration } \\
\text { of cyclohexene }\end{array}$ & $\begin{array}{l}\mathrm{T}_{5} \\
(\mathrm{~K})\end{array}$ & $\begin{array}{c}\mathrm{P}_{5} \\
\text { (atm) }\end{array}$ & $\begin{array}{l}\text { Reaction } \\
\text { time } \\
(\mu \mathrm{s})\end{array}$ & $\begin{array}{l}{\left[\mathrm{CH}_{4}\right]_{t} /} \\
{[\mathrm{TMS}]_{0}}\end{array}$ & $\begin{array}{l}{\left[\mathrm{C}_{2} \mathrm{H}_{4}\right]_{\mathrm{t}} /} \\
{[\mathrm{TMS}]_{0}}\end{array}$ & $\begin{array}{c}{\left[\mathrm{C}_{2} \mathrm{H}_{6}\right]_{\mathrm{t}} /} \\
{[\mathrm{TMS}]_{0}}\end{array}$ & $\begin{array}{c}{\left[\mathrm{C}_{3} \mathrm{H}_{6}\right]_{\mathrm{t}} /} \\
{[\mathrm{TMS}]_{0}}\end{array}$ & $\begin{array}{l}{[\mathrm{TMS}]_{\mathrm{t}} /} \\
{[\mathrm{TMS}]_{0}}\end{array}$ \\
\hline 1 & 400 & 0.025 & 0.025 & 1058 & 14.7 & 544 & 0.0311 & 0.0211 & 0.0026 & 0.0038 & 0.941 \\
\hline 2 & 500 & 0.020 & 0.020 & 1061 & 16.5 & 328 & 0.0292 & 0.0123 & 0.0017 & 0.0032 & 0.954 \\
\hline 3 & 205 & 0.048 & 0.048 & 1063 & 14.9 & 330 & 0.0292 & 0.0123 & 0.0017 & 0.0032 & 0.954 \\
\hline 4 & 525 & 0.019 & 0.019 & 1065 & 16.4 & 435 & 0.0118 & 0.0161 & 0.0039 & 0.0052 & 0.963 \\
\hline 5 & 530 & 0.019 & 0.019 & 1066 & 15.6 & 445 & 0.0131 & 0.0160 & 0.0039 & 0.0052 & 0.962 \\
\hline 6 & 450 & 0.022 & 0.022 & 1074 & 16.6 & 476 & 0.0606 & 0.0358 & 0.0072 & 0.0070 & 0.889 \\
\hline 7 & 550 & 0.018 & 0.018 & 1084 & 13.8 & 470 & 0.0790 & 0.0523 & 0.0088 & 0.0065 & 0.853 \\
\hline 8 & 550 & 0.018 & 0.018 & 1091 & 13.5 & 826 & 0.1671 & 0.2367 & 0.0135 & 0.0075 & 0.575 \\
\hline 9 & 300 & 0.033 & 0.033 & 1096 & 13.9 & 600 & 0.1376 & 0.1338 & 0.0113 & 0.0071 & 0.710 \\
\hline 10 & 350 & 0.029 & 0.029 & 1106 & 16.7 & 609 & 0.1735 & 0.1432 & 0.0126 & 0.0091 & 0.662 \\
\hline 11 & 325 & 0.030 & 0.030 & 1108 & 14.9 & 620 & 0.1681 & 0.2504 & 0.0139 & 0.0075 & 0.560 \\
\hline 12 & 350 & 0.029 & 0.029 & 1117 & 16.5 & 658 & 0.1751 & 0.2913 & 0.0116 & 0.0075 & 0.514 \\
\hline 13 & 200 & 0.050 & 0.050 & 1118 & 12.2 & 868 & 0.2280 & 0.3818 & 0.0096 & 0.0065 & 0.374 \\
\hline 14 & 325 & 0.030 & 0.030 & 1121 & 16.0 & 659 & 0.2140 & 0.3027 & 0.0140 & 0.0071 & 0.462 \\
\hline 15 & 200 & 0.050 & 0.050 & 1122 & 10.6 & 766 & 0.1980 & 0.3479 & 0.0122 & 0.0070 & 0.435 \\
\hline 16 & 275 & 0.036 & 0.036 & 1123 & 14.9 & 760 & 0.2496 & 0.3973 & 0.0083 & 0.0074 & 0.337 \\
\hline 17 & 300 & 0.033 & 0.033 & 1124 & 14.4 & 590 & 0.1911 & 0.2688 & 0.0170 & 0.0079 & 0.515 \\
\hline 18 & 300 & .033 & 0.033 & 1125 & 15.9 & 800 & 0.2293 & 0.3787 & 0.0099 & 0.0086 & 0.373 \\
\hline 19 & 275 & 0.036 & 0.036 & 1126 & 15.2 & 752 & 0.2495 & 0.3627 & 0.0100 & 0.0090 & 0.369 \\
\hline 20 & 275 & 0.036 & 0.036 & 1127 & 15.3 & 780 & 0.2571 & 0.3816 & 0.0106 & 0.0078 & 0.343 \\
\hline 21 & 225 & 044 & 0.044 & 1129 & 13.6 & 844 & 0.2688 & 0.4002 & 0.0098 & 0.0081 & 0.313 \\
\hline 22 & 250 & .040 & 0.040 & 1130 & 15.6 & 720 & 0.2637 & 0.3768 & 0.0096 & 0.0079 & 0.342 \\
\hline 23 & 300 & 0.033 & 0.033 & 1131 & 16.0 & 790 & 0.2689 & 0.3911 & 0.0111 & 0.0085 & 0.320 \\
\hline 24 & 250 & 0.040 & 0.040 & 1138 & 14.3 & 700 & 0.2457 & 0.4278 & 0.0090 & 0.0089 & 0.309 \\
\hline 25 & 200 & 050 & 0.050 & 1141 & 13.1 & 830 & 0.2711 & 0.4314 & 0.0084 & 0.0077 & 0.281 \\
\hline 26 & 225 & 044 & 0.044 & 1143 & 14.3 & 852 & 0.3085 & 0.4056 & 0.0101 & 0.0094 & 0.266 \\
\hline 27 & 250 & 0.040 & 0.040 & 1151 & 14.0 & 710 & 0.2918 & 0.3856 & 0.0096 & 0.0072 & 0.306 \\
\hline 28 & 200 & 0.050 & 0.050 & 1153 & 13.6 & 898 & 0.2945 & 0.4853 & 0.0077 & 0.0097 & 0.203 \\
\hline 29 & 225 & .040 & 0.040 & 1162 & 13.8 & 838 & 0.2724 & 0.4605 & 0.0095 & 0.0067 & 0.251 \\
\hline 30 & 200 & .050 & & 1176 & 13.4 & 778 & 0.3422 & 0.4442 & 0.0111 & 0.0113 & 0.191 \\
\hline 31 & 200 & 0.050 & 0.050 & 1179 & 13.9 & 778 & 0.3685 & 0.4771 & 0.0120 & 0.0122 & 0.130 \\
\hline 32 & 325 & 0.030 & 0.030 & 1194 & 21.8 & 880 & 0.3766 & 0.4061 & 0.0078 & 0.0099 & 0.200 \\
\hline 33 & 375 & 0.026 & 0.026 & 1194 & 22.8 & 870 & 0.4249 & 0.4739 & 0.0105 & 0.0090 & 0.082 \\
\hline
\end{tabular}

used as a carrier gas in the analysis. The sensitivity of the flame ionization detector (FID) towards all the reactants and products were calibrated over a known range of concentrations. The concentration/mole fraction of left-out reactant and other products were calculated using the known sensitivity factors obtained in the calibration and the areas under each peak. A qualitative analysis was also carried out by using a Bruker's VERTEX 70 FTIR spectrometer.

\subsection{Materials and chemicals}

TMS (GC grade with $>99 \%$ purity) and cyclohexene (reagent plus grade $99 \%$ purity) used in these experiments were purchased from Sigma Aldrich. TMS and cyclohexene were further purified by several cycles of freeze-pump-thaw method. Analysis of TMS and cyclohexene by gas chromatography showed no distinguishable impurities. Methane (99.5\%), ethylene $(99.5 \%)$, ethane $(99.5 \%)$, propylene $(99.5 \%), 1,3-$ butadiene $(99.5 \%)$ and the high purity helium gas $(99.995 \%)$ from Praxair Inc. were used as such in our experiments.

\section{Results and Discussion}

To understand the distribution of reaction products, 33 experiments were carried out with gas mixtures containing 10 Torr of TMS and 10 Torr of cyclohexene in argon as described in the experimental section, covering the temperature range of 1058-1194 K. Typical reaction times were $330-1000 \mu$ s and the pressure was 
varied between 11 and $23 \mathrm{~atm}$. Detailed conditions of each experiment and the normalized yields of products are given in table 1 . The detectable products observed in the decomposition of TMS are methane $\left(\mathrm{CH}_{4}\right)$, ethylene $\left(\mathrm{C}_{2} \mathrm{H}_{4}\right)$, ethane $\left(\mathrm{C}_{2} \mathrm{H}_{6}\right)$ and propylene $\left(\mathrm{C}_{3} \mathrm{H}_{6}\right)$. A gas chromatogram of a post shock mixture of TMS decomposed at $1151 \mathrm{~K}$ is shown in figure 3 . The concentration ratios of 1,3-butadiene and cyclohexene were used to determine the reflected shock temperature. In these experiments, ethylene is the product of both the reactant TMS and internal standard. This was confirmed by decomposing TMS alone behind the reflected shock waves in the studied temperature range and ethylene was observed to be one of the products listed before. The contributions of cyclohexene towards the total concentration of ethylene was computed by measuring the concentration of 1,3-butadiene, which was formed in equal concentrations via reaction 1 . It was further confirmed that, 1,3-butadiene does not decompose in the investigated range of the temperatures, by carrying out its decomposition independently. Skinner et al., ${ }^{37}$ and Hidaka et al., ${ }^{38}$ also have reported that 1,3-butadiene does not decompose in this temperature range. Therefore, we have subtracted the yield of ethylene due to the decomposition of cyclohexene, which is essentially equal to the concentration of 1,3-butadiene from the total yield of ethylene, to get the ethylene yield due to the decomposition of TMS alone.

We have carried out FTIR analysis, to find out the silicon containing species and hydrocarbons. A FTIR spectrum of the post shock mixture of TMS in argon, decomposed at $1179 \mathrm{~K}$ is shown in figure 4 . The Si$\mathrm{CH}_{3}$ group is easily recognized with a sharp peak at $1260 \mathrm{~cm}^{-1}$, and the peaks around 1447 and $947 \mathrm{~cm}^{-1}$ indicate the presence of olefins. The peak at $2964 \mathrm{~cm}^{-1}$ shows the presence of hydrocarbons.

The decay of the reactant and formation of products are shown as a function of temperature in figure 5 . Concentrations of products methane and ethylene are observed to be continuously increasing with the temperature. The ethane concentration was observed to be increasing up to $\approx 1150 \mathrm{~K}$ and then decreasing due to several other reactions. Propylene concentrations seem to be increasing upto $1120 \mathrm{~K}$ and then more or less constant thereafter.

The rate coefficients for the decomposition of TMS were calculated by using the following equation

$$
k_{\text {total }}=-\ln \left\{[T M S]_{t} /[T M S]_{0}\right\} / t
$$

where $[\mathrm{TMS}]_{\mathrm{t}}$ and $[\mathrm{TMS}]_{0}$ are the experimentally quantified concentration of TMS at the end of the reaction time ' $t$ ' and initial concentration respectively. The obtained rate coefficients were used to plot the Arrhenius equation and are shown in figure 6 . The rate coefficients are observed to be non-linear across the studied temperature range. Therefore, the data were fit to the Arrhenius equation in two different temperature ranges i.e., 1058-1130K and 1130-1194K using linear least squares method. The temperature dependent

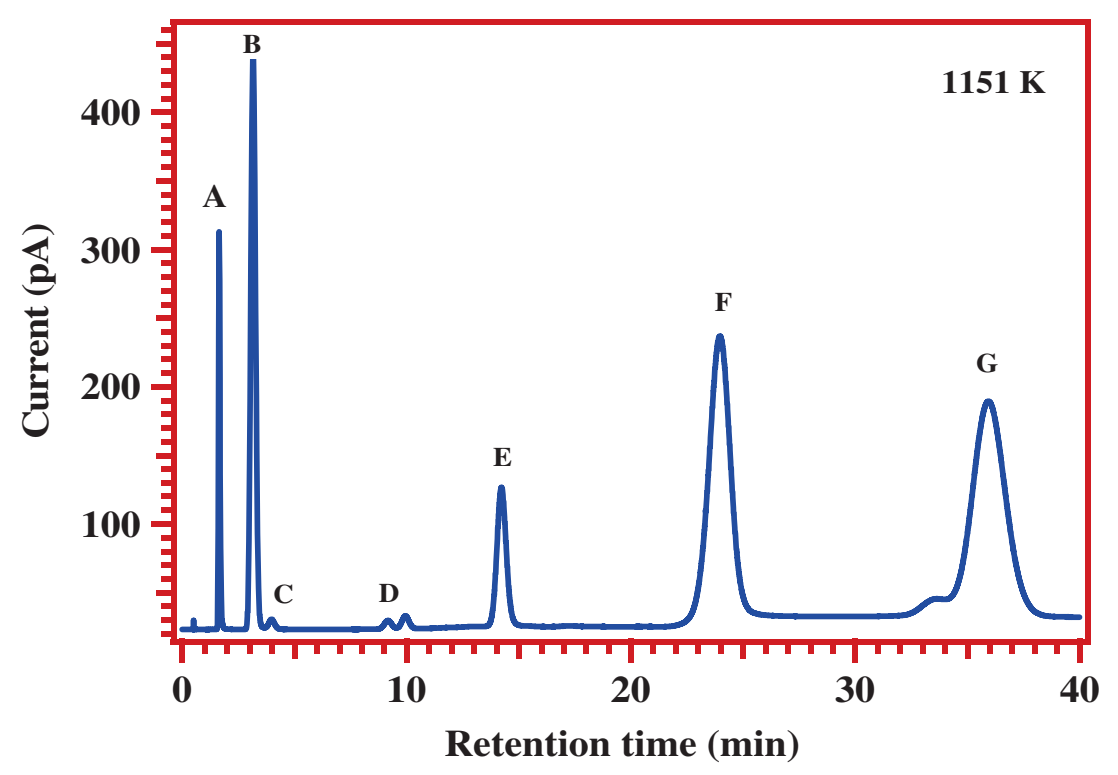

Figure 3. Gas chromatogram showing the products of the post shock mixture of the experiment carried out at $1151 \mathrm{~K}$. The peaks labeled in the chromatogram are (A) methane, (B) ethylene, (C) ethane, (D) propylene, (E) 1,3-butadiene, (F) tetramethylsilane and $(\mathbf{G})$ cyclohexene. 


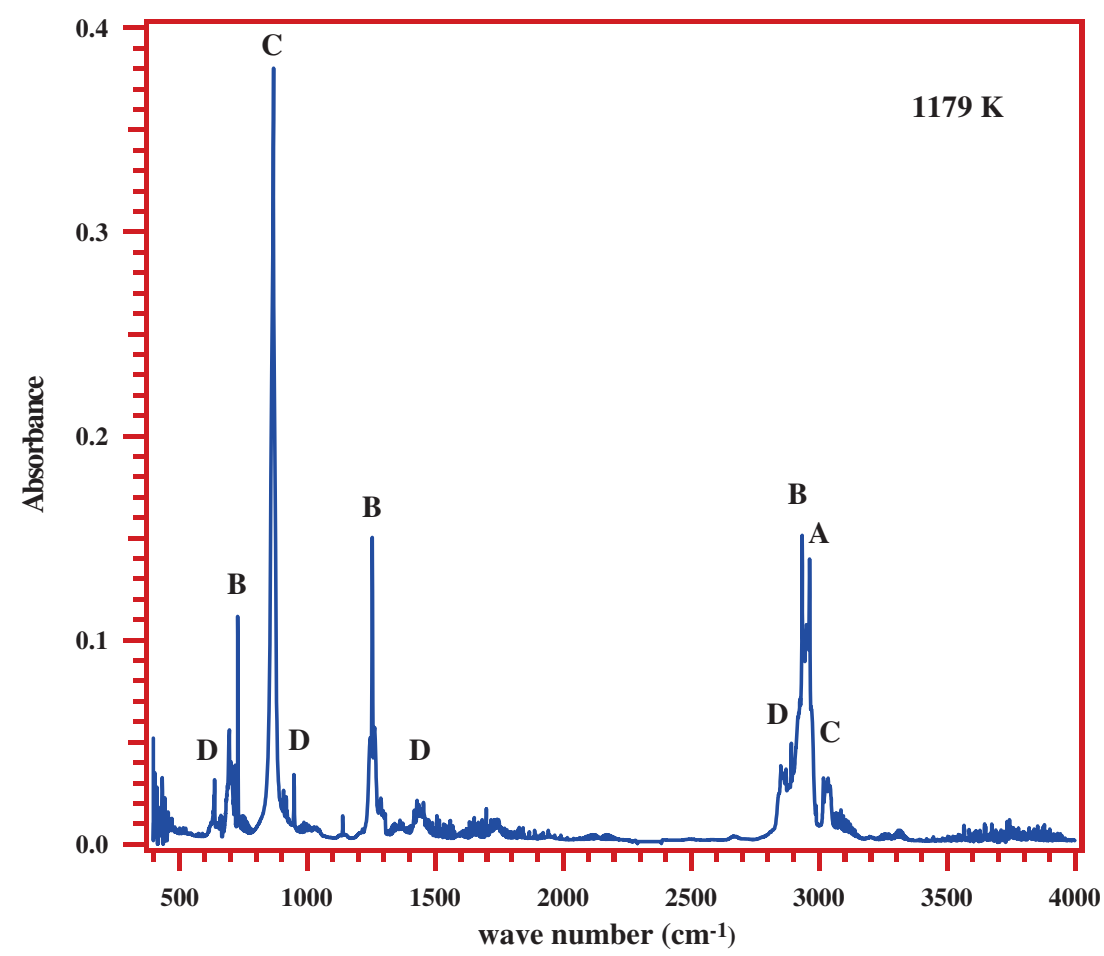

Figure 4. FT-IR spectrum of the post shock mixture of tetramethylsilane diluted in argon when the experiment was carried out at $1179 \mathrm{~K}$. The peaks labeled in the spectrum are (A) methane, (B) tetramethylsilane, $(\mathbf{C})$ ethylene, and (D) propylene.

rate coefficients obtained are $\mathrm{k}_{\text {total }}(1058-1130 \mathrm{~K})=$ $(4.61 \pm 0.70) \times 10^{18} \exp \left(-\left(79.9 \mathrm{kcal} \mathrm{mol}^{-1} \pm 3.5\right) / \mathrm{RT}\right)$ $\mathrm{s}^{-1}, \mathrm{k}_{\text {total }}(1130-1194 \mathrm{~K})=(1.33 \pm 0.19) \times 10^{6} \exp$ $\left(-\left(15.3 \mathrm{kcal} \mathrm{mol}^{-1} \pm 3.5\right) / \mathrm{RT}\right) \mathrm{s}^{-1}$ where, $\mathrm{R}$ is expressed in the units of kcal $\mathrm{K}^{-1} \mathrm{~mol}^{-1}$. The errors reported here are the errors obtained in the linear least squares fit of the data. The nonlinearity in the Arrhenius plot is due to many reaction channels in the decomposition process of TMS. At high temperature region TMS undergo unimolecular dissociation as well as bimolecular reactions ${ }^{45,46}\left(\mathrm{CH}_{3}+\left(\mathrm{CH}_{3}\right)_{4} \mathrm{Si} \rightarrow \mathrm{CH}_{4}+\right.$ $\left.\left(\mathrm{CH}_{3}\right)_{3} \mathrm{SiCH}_{2},\left(\mathrm{CH}_{3}\right)_{4} \mathrm{Si}+\mathrm{H} \rightarrow \mathrm{H}_{2}+\left(\mathrm{CH}_{3}\right)_{3} \mathrm{SiCH}_{2}\right)$. As the consumption of the reactant is because of both the competitive or parallel reactions, the Arrhenius plot is expected to be non-linear, which is the case as well. In addition, the products ethane and propylene were observed to be increasing upto $1125 \mathrm{~K}$ and then start decreasing as they get dissociated into other products, which may be one of the reasons for sudden deviation in the Arrhenius plot. The measured rate coefficient of reaction $\mathrm{R} 1$ from the present experiments is mostly valid in the temperature range of 1058-1194 K only. Even within the studied temperature range the trends are different between $1058-1130 \mathrm{~K}$ and 1130 $1194 \mathrm{~K}$ (figure 6). Therefore, the extrapolation may not be valid.
The rate coefficients for the formation of methane were computed by using the following relation ${ }^{39}$

$$
k_{\text {methane }}=\frac{[\text { Methane }]_{t}}{[T M S]_{0}-[T M S]_{t}} \times k \text { total }
$$

where $[\text { Methane }]_{t}$ is the concentration of methane at the end of reaction time ' $t$ '. The experimentally obtained rate coefficients were used to plot the Arrhenius equation and are shown in figure 7. The data were fit using linear least squares method and the temperature dependent rate coefficient for the formation of methane was obtained to be $k_{\text {methane }}(1058-1194 \mathrm{~K})=(4.36 \pm 1.23)$ $\times 10^{14} \exp \left(-\left(61.9 \mathrm{kcal} \mathrm{mol}^{-1} \pm 4.9\right) / \mathrm{RT}\right) \mathrm{s}^{-1}$. The activation energy for the formation of methane is determined to be $62.0 \mathrm{kcal} \mathrm{mol}^{-1}$, which is about $6 \mathrm{kcal}$ $\mathrm{mol}^{-1}$ lower than the value reported by Clifford et al., ${ }^{19}$ As mentioned in the introduction, Baldwin et al., ${ }^{20}$ have reported two rate expressions for the two different range of temperatures. The activation energy obtained in our experiments is $4.5 \mathrm{kcal} \mathrm{mol}^{-1}$ higher than the one reported by Baldwin et al.,$^{20}$ in the temperature range of $840-950 \mathrm{~K}$. However, it is $23 \mathrm{kcal} \mathrm{mol}^{-1}$ lower than the activation energy reported in the temperature range of $955-1055 \mathrm{~K}$. The value of rate coefficient for the formation of methane obtained in the present work at 

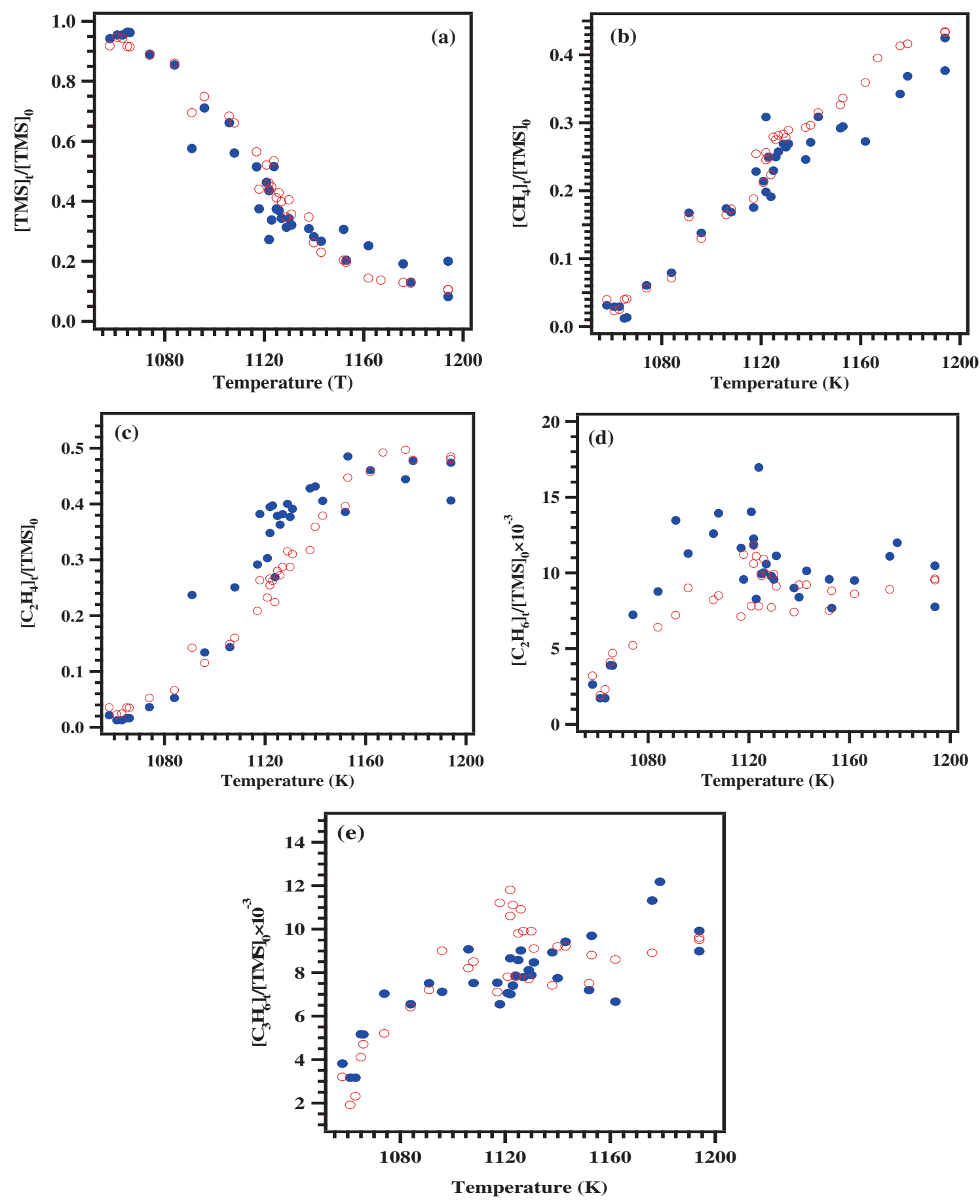

Figure 5. The complete decomposition profile of TMS behind the reflected shock waves and the profiles of the products obtained in the temperature range of 1058-1194 K. The filled symbols correspond to the experimental yields and open symbols correspond to the simulated data. The plots labeled are (a) tetramethylsilane (b) methane (c) ethylene (d) ethane and (e) propylene.

$1058 \mathrm{~K}$ is almost two orders of magnitude higher than that reported at $1055 \mathrm{~K}$. The rate coefficients reported in earlier investigation were obtained using pulsed stirred flow reactor wherein the reaction times were varied between 13 and $120 \mathrm{~s}$. The secondary chemistry and the wall effects will definitely be significant in their studies for such long reaction times. However, in the present experiments, the reaction time was a maximum of $1 \mathrm{~ms}$. One of the advantages of using the SPST technique is that the wall effects are almost negligible in such short durations. This could be one of the reasons for such a difference in rate coefficients. In addition, many other experimental uncertainties could also contribute. 


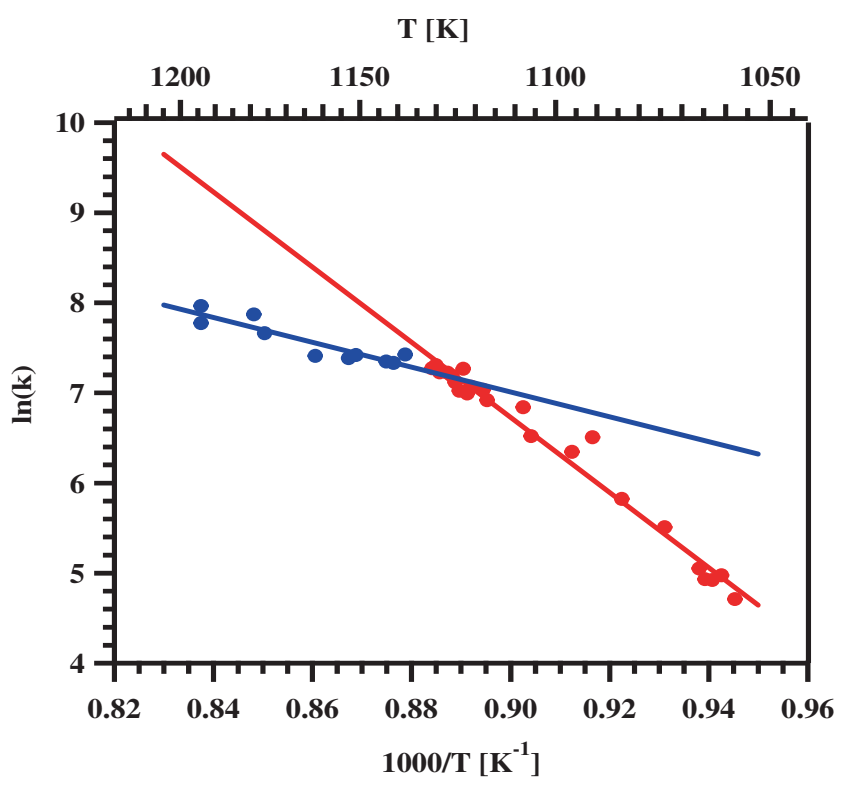

Figure 6. Arrhenius plot for the overall decomposition of TMS in the temperature range of 1058-1194 K. The rate coefficients were calculated using the equation $k_{\text {total }}=-\frac{\ln \left\{[T M S]_{t} /[T M S]_{0}\right\}}{t}$. The obtained temperature dependent rate coefficients for two different temperature ranges are $\mathrm{k}_{\text {total }}(1058-1130 \mathrm{~K})=(4.61 \pm 0.70) \times 10^{18} \exp$ $\left(-\left(79.9 \mathrm{kcal} \mathrm{mol}^{-1} \pm 3.5\right) / \mathrm{RT}\right) \mathrm{s}^{-1}, \mathrm{k}_{\text {total }}(1130-1194 \mathrm{~K})=$ $(1.33 \pm 0.19) \times 10^{6} \exp \left(-\left(15.3 \mathrm{kcal} \mathrm{mol}^{-1} \pm 3.5\right) / \mathrm{RT}\right) \mathrm{s}^{-1}$.

The formation of Si-C cannot be understood by this study because $\mathrm{SiC}$ growth was not focused in the present investigation. Various studies are available on the pyrolysis of neopentane in literature. ${ }^{40-43}$ The available studies report that the primary dissociation of neopentane also happens via $\mathrm{C}-\mathrm{C}$ ( $\mathrm{Si}-\mathrm{C}$ bond cleavage in TMS) bond cleavage by forming methyl and tertbutyl radicals. Taylor et al., ${ }^{41}$ studied in detail on the homogeneous gas phase pyrolysis of neopentane using a reactor in the temperature range of $920-1070 \mathrm{~K}$. The reaction products observed on pyrolysis of neopentane are hydrogen, methane, ethane, ethylene, propylene, allene, methylacetylene, 2-methyl-1-butene, 2-methyl2-butene, isoprene and isobutylene. The initial ratedetermining reaction is the unimolecular decomposition of neopentane to form t-butyl and methyl radicals. Hydrogen, ethane and methane appear to form by radical combinations, which is also the case in the present study. In the decomposition of neopentane, the formation of methane happens via hydrogen abstraction from the reactant by $\mathrm{CH}_{3}$ radicals; isobutylene is formed by decomposition of the t-butyl radical; ethylene, propylene, and allene are formed by degradation of isobutylene; and the other products by a variety of reactions. The formation of methane in the decomposition of TMS happen via the same mechanism. i.e., abstraction

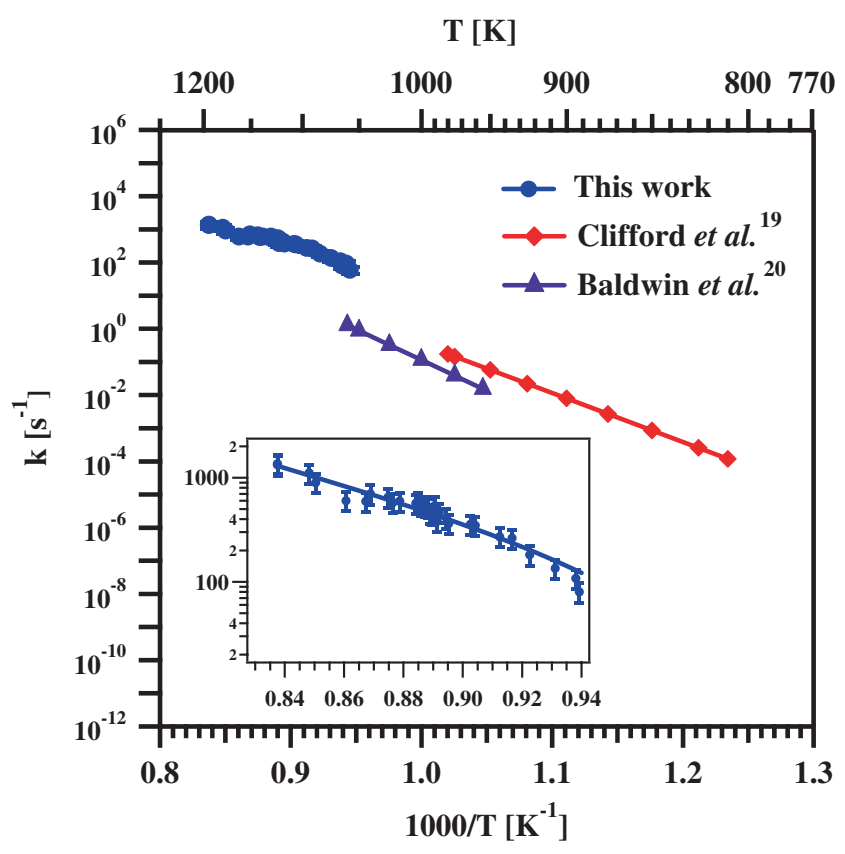

Figure 7. Arrhenius plot for the formation of methane in the decomposition of TMS. The obtained temperature dependent rate coefficient for the entire experimental temperature range is $k_{\text {methane }}=(4.36 \pm 9.72) \times 10^{14} \mathrm{exp}$ $\left(-\left(61.9 \mathrm{kcal} \mathrm{mol}^{-1} \pm 4.9\right) / \mathrm{RT}\right) \mathrm{s}^{-1}$. The insert is the zoom of the data obtained in the present experiments.

of hydrogen from the reactant by $\mathrm{CH}_{3}$ radicals. The temperature dependent rate coefficients for the overall decomposition of TMS and neopentane are given in table 2 for the ready comparison. The activation energies for the overall decomposition of TMS and neopentane are just same $\left(80 \mathrm{kcal} \mathrm{mol}^{-1}\right)$ in the temperature range of $1000-1100 \mathrm{~K}$. This could be the obvious reason for the similar mechanism between TMS and neopentane.

\subsection{Kinetic simulations}

To understand the reaction mechanism in the decomposition of TMS, a reaction kinetic scheme is proposed with 21 reaction species and 38 elementary reactions. The proposed reaction scheme is given in table 3 . The reaction mechanism proposed earlier ${ }^{19-21}$ was also included in the present kinetic scheme. The rate coefficients for all the proposed reactions except for R1 were taken from the literature. ${ }^{46-71}$ The rate coefficient obtained for the formation of methane (R1) in the present investigation was used in the simulations. The rate coefficients for the proposed reactions are given in $k=\mathrm{A} \exp \left(-\mathrm{E}_{\mathrm{a}} / \mathrm{RT}\right)$ or $k=\mathrm{AT}^{\mathrm{n}} \exp \left(-\mathrm{E}_{\mathrm{a}} / \mathrm{RT}\right)$ formats, where A factors are given in $\mathrm{s}^{-1}$ and $\mathrm{cm}^{3} \mathrm{~mol}^{-1} \mathrm{~s}^{-1}$ for first and second order reactions respectively, and 
Table 2. The comparison of temperature dependent rate coefficients for total decomposition of TMS in the present investigation and earlier studies on neopentane.

\begin{tabular}{lcccccc}
\hline \multicolumn{3}{c}{ Total decomposition of TMS } & & \multicolumn{3}{c}{ Total decomposition of neopentane } \\
\cline { 1 - 2 } Temperature $(\mathrm{K})$ & $\mathrm{A}\left(\mathrm{s}^{-1}\right)$ & $\mathrm{E}_{\mathrm{a}}\left(\mathrm{kcal} \mathrm{mol}^{-1}\right)$ & & Temperature $(\mathrm{K})$ & $\mathrm{A}\left(\mathrm{s}^{-1}\right)$ & $\mathrm{E}_{\mathrm{a}}\left(\mathrm{kcal} \mathrm{mol}^{-1}\right)$ \\
\hline $1058-1130 \mathrm{~K}^{\mathrm{a}}$ & $(4.61 \pm 0.70) \times 10^{18 \mathrm{a}}$ & $79.9^{\mathrm{a}}$ & & $920-1070 \mathrm{~K}^{41}$ & $7.94 \times 10^{1641}$ & $80.5^{41}$ \\
$1130-1194 \mathrm{~K}^{\mathrm{b}}$ & $(1.33 \pm 0.19) \times 10^{6 \mathrm{~b}}$ & $15.3^{\mathrm{b}}$ & & $1260-1462 \mathrm{~K}^{42}$ & $8.66 \times 10^{1242}$ & $60.5^{42}$ \\
& & & & $793-953 \mathrm{~K}^{43}$ & $5.01 \times 10^{1743}$ & $85.1^{43}$ \\
\hline
\end{tabular}

${ }^{\mathrm{a}}$ Total decomposition of TMS at 1058-1130 K in present study, ${ }^{\mathrm{b}}$ Total decomposition of TMS at 1130-1149K in present study, ${ }^{41}$ Taylor et al.,${ }^{42}$ Sivaramakrishnan et al. ${ }^{43}$ Pacey.

Table 3. Proposed reaction scheme for the decomposition of TMS with 21 reaction species and 38 elementary reactions. ${ }^{\mathrm{a}}$

\begin{tabular}{|c|c|c|c|c|c|}
\hline No & Reaction & A & $\mathrm{n}$ & $\mathrm{E}_{\mathrm{a}}$ & Reference \\
\hline R1 & $\left(\mathrm{CH}_{3}\right)_{4} \mathrm{Si} \rightarrow \mathrm{CH}_{3}+\left(\mathrm{CH}_{3}\right)_{3} \mathrm{Si}$ & $4.36 \times 10^{14}$ & 0.00 & 61.98 & This work \\
\hline R2 & $\mathrm{CH}_{3}+\left(\mathrm{CH}_{3}\right)_{4} \mathrm{Si} \rightarrow \mathrm{CH}_{4}+\left(\mathrm{CH}_{3}\right)_{3} \mathrm{SiCH}_{2}$ & $1.99 \times 10^{11}$ & 0.00 & 9.60 & 45 \\
\hline R3 & $\left(\mathrm{CH}_{3}\right)_{3} \mathrm{SiCH}_{2} \rightarrow \mathrm{CH}_{3}+\left(\mathrm{CH}_{3}\right)_{2} \mathrm{SiCH}_{2}$ & $1.00 \times 10^{15}$ & 0.00 & 50.66 & 20 \\
\hline R4 & $\left(\mathrm{CH}_{3}\right)_{4} \mathrm{Si}+\mathrm{H} \rightarrow \mathrm{H}_{2}+\left(\mathrm{CH}_{3}\right)_{3} \mathrm{SiCH}_{2}$ & $4.71 \times 10^{5}$ & 2.65 & 4.88 & 46 \\
\hline R5 & $\left(\mathrm{CH}_{3}\right)_{3} \mathrm{Si} \rightarrow\left(\mathrm{CH}_{3}\right)_{2} \mathrm{Si}+\mathrm{CH}_{3}$ & $1.00 \times 10^{15}$ & 0.00 & 52.80 & 20 \\
\hline R6 & $\mathrm{CH}_{3}+\mathrm{CH}_{3} \rightarrow \mathrm{C}_{2} \mathrm{H}_{6}$ & $4.47 \times 10^{13}$ & -0.69 & 0.17 & 47 \\
\hline R7 & $\left(\mathrm{CH}_{3}\right)_{2} \mathrm{Si} \rightarrow \mathrm{CH}_{3} \mathrm{Si}+\mathrm{CH}_{3}$ & $1.00 \times 10^{15}$ & 0.00 & 52.80 & 20 \\
\hline R8 & $\mathrm{CH}_{3}+\mathrm{CH}_{3} \rightarrow \mathrm{C}_{2} \mathrm{H}_{5}+\mathrm{H}$ & $2.40 \times 10^{13}$ & 0.00 & 12.88 & 48 \\
\hline R9 & $\mathrm{CH}_{3}+\mathrm{CH}_{3} \rightarrow \mathrm{C}_{2} \mathrm{H}_{4}+\mathrm{H}_{2}$ & $9.90 \times 10^{15}$ & 0.00 & 32.98 & 49 \\
\hline R10 & $\mathrm{C}_{2} \mathrm{H}_{5}+\mathrm{H} \rightarrow \mathrm{C}_{2} \mathrm{H}_{4}+\mathrm{H}_{2}$ & $1.81 \times 10^{14}$ & 0.00 & 0.00 & 50 \\
\hline R11 & $\mathrm{C}_{2} \mathrm{H}_{6}+\mathrm{CH}_{3} \rightarrow \mathrm{C}_{2} \mathrm{H}_{5}+\mathrm{CH}_{4}$ & $3.02 \times 10^{12}$ & 0.00 & 13.59 & 51 \\
\hline R12 & $\mathrm{C}_{2} \mathrm{H}_{5} \rightarrow \mathrm{C}_{2} \mathrm{H}_{4}+\mathrm{H}$ & $3.06 \times 10^{10}$ & 0.95 & 36.94 & 52 \\
\hline R13 & $\mathrm{C}_{2} \mathrm{H}_{5}+\mathrm{C}_{2} \mathrm{H}_{5} \rightarrow \mathrm{C}_{2} \mathrm{H}_{4}+\mathrm{C}_{2} \mathrm{H}_{6}$ & $1.45 \times 10^{12}$ & 0.00 & 0.00 & 53 \\
\hline R14 & $\mathrm{H}_{2}+\mathrm{Ar} \rightarrow \mathrm{H}+\mathrm{H}+\mathrm{Ar}$ & $5.33 \times 10^{14}$ & 0.00 & 96.01 & 54 \\
\hline R15 & $\mathrm{C}_{2} \mathrm{H}_{4}+\mathrm{CH}_{3} \rightarrow \mathrm{C}_{3} \mathrm{H}_{6}+\mathrm{H}$ & $2.00 \times 10^{13}$ & 0.00 & 10.00 & 50 \\
\hline R16 & $\mathrm{C}_{3} \mathrm{H}_{6}+\mathrm{H} \rightarrow \mathrm{C}_{2} \mathrm{H}_{4}+\mathrm{CH}_{3}$ & $1.32 \times 10^{12}$ & 1.50 & 2.01 & 55 \\
\hline R17 & $\mathrm{CH}_{4} \rightarrow \mathrm{CH}_{3}+\mathrm{H}$ & $7.80 \times 10^{14}$ & 0.00 & 103.83 & 50 \\
\hline R18 & $\mathrm{CH}_{4}+\mathrm{CH}_{3} \rightarrow \mathrm{C}_{2} \mathrm{H}_{6}+\mathrm{H}$ & $2.98 \times 10^{11}$ & 1.00 & 44.91 & 56 \\
\hline R19 & $\mathrm{C}_{3} \mathrm{H}_{6} \rightarrow \mathrm{CH}_{3}+\mathrm{C}_{2} \mathrm{H}_{3}$ & $8.00 \times 10^{14}$ & 0.00 & 88.03 & 55 \\
\hline R20 & $\mathrm{C}_{2} \mathrm{H}_{5}+\mathrm{H} \rightarrow \mathrm{C}_{2} \mathrm{H}_{6}$ & $4.50 \times 10^{13}$ & 0.00 & 0.00 & 57 \\
\hline R21 & $\mathrm{C}_{2} \mathrm{H}_{3}+\mathrm{H}_{2} \rightarrow \mathrm{C}_{2} \mathrm{H}_{4}+\mathrm{H}$ & $2.04 \times 10^{14}$ & 2.56 & 5.03 & 58 \\
\hline R22 & $\mathrm{CH}_{3}+\mathrm{Ar} \rightarrow \mathrm{CH}_{2}+\mathrm{H}+\mathrm{Ar}$ & $2.82 \times 10^{15}$ & 0.00 & 84.56 & 59 \\
\hline $\mathrm{R} 23$ & $\mathrm{CH}_{3}+\mathrm{H} \rightarrow \mathrm{CH}_{2}+\mathrm{H}_{2}$ & $6.02 \times 10^{13}$ & 0.00 & 15.10 & 53 \\
\hline R24 & $\mathrm{CH}_{3}+\mathrm{CH}_{2} \rightarrow \mathrm{C}_{2} \mathrm{H}_{4}+\mathrm{H}$ & $6.02 \times 10^{13}$ & 0.00 & 0.00 & 60 \\
\hline R25 & $\mathrm{CH}_{2}+\mathrm{H} \rightarrow \mathrm{CH}+\mathrm{H}_{2}$ & $1.63 \times 10^{14}$ & 0.00 & 0.00 & 61 \\
\hline R26 & $\mathrm{CH}_{3}+\mathrm{CH} \rightarrow \mathrm{C}_{2} \mathrm{H}_{3}+\mathrm{H}$ & $3.00 \times 10^{13}$ & 0.00 & 0.00 & 62 \\
\hline R27 & $\mathrm{CH}_{3}+\mathrm{Ar} \rightarrow \mathrm{CH}+\mathrm{H}_{2}+\mathrm{Ar}$ & $6.90 \times 10^{14}$ & 0.00 & 82.50 & 63 \\
\hline $\mathrm{R} 28$ & $\mathrm{CH}_{4}+\mathrm{H} \rightarrow \mathrm{CH}_{3}+\mathrm{H}_{2}$ & $1.77 \times 10^{14}$ & 0.00 & 13.78 & 63 \\
\hline R29 & $\mathrm{C}_{2} \mathrm{H}_{4}+\mathrm{C}_{2} \mathrm{H}_{5} \rightarrow \mathrm{C}_{2} \mathrm{H}_{6}+\mathrm{C}_{2} \mathrm{H}_{3}$ & $1.58 \times 10^{11}$ & 0.00 & 14.86 & 64 \\
\hline R30 & $\mathrm{CH}_{4}+\mathrm{H} \rightarrow \mathrm{CH}_{3}+2 \mathrm{H}$ & $4.40 \times 10^{\circ}$ & 0.00 & 7.88 & 65 \\
\hline R31 & $\mathrm{C}_{2} \mathrm{H}_{5}+\mathrm{C}_{3} \mathrm{H}_{6} \rightarrow \mathrm{C}_{2} \mathrm{H}_{6}+\mathrm{n}-\mathrm{C}_{3} \mathrm{H}_{5}$ & $6.92 \times 10^{10}$ & 0.00 & 5.19 & 66 \\
\hline R32 & $\mathrm{C}_{3} \mathrm{H}_{6}+\mathrm{H} \rightarrow \mathrm{n}-\mathrm{C}_{3} \mathrm{H}_{7}$ & $2.50 \times 10^{11}$ & 0.51 & 2.62 & 67 \\
\hline R33 & $\mathrm{C}_{3} \mathrm{H}_{6}+\mathrm{H} \rightarrow$ iso- $_{3} \mathrm{H}_{7}$ & $4.24 \times 10^{11}$ & 0.51 & 1.23 & 67 \\
\hline R34 & iso- $\mathrm{C}_{3} \mathrm{H}_{7} \rightarrow \mathrm{C}_{2} \mathrm{H}_{4}+\mathrm{CH}_{3}$ & $1.00 \times 10^{12}$ & 0.00 & 34.58 & 68 \\
\hline R35 & iso- $\mathrm{C}_{3} \mathrm{H}_{7}+\mathrm{C}_{2} \mathrm{H}_{5} \rightarrow \mathrm{C}_{2} \mathrm{H}_{6}+\mathrm{C}_{3} \mathrm{H}_{6}$ & $3.13 \times 10^{10}$ & -0.35 & 0.00 & 69 \\
\hline R36 & $\mathrm{n}-\mathrm{C}_{3} \mathrm{H}_{7} \rightarrow \mathrm{C}_{2} \mathrm{H}_{4}+\mathrm{CH}_{3}$ & $2.70 \times 10^{13}$ & 0.00 & 30.04 & 70 \\
\hline R37 & $\mathrm{n}-\mathrm{C}_{3} \mathrm{H}_{7}+\mathrm{C}_{2} \mathrm{H}_{5} \rightarrow \mathrm{C}_{2} \mathrm{H}_{6}+\mathrm{C}_{3} \mathrm{H}_{6}$ & $1.45 \times 10^{12}$ & 0.00 & 0.00 & 69 \\
\hline R38 & $\mathrm{n}-\mathrm{C}_{3} \mathrm{H}_{5}+\mathrm{H}_{2} \rightarrow \mathrm{C}_{3} \mathrm{H}_{6}+\mathrm{H}$ & $6.90 \times 10^{14}$ & 2.38 & 82.50 & 71 \\
\hline
\end{tabular}

${ }^{a}$ Rate expressions are given in the form of $\mathrm{k}=\mathrm{A} \exp \left(-\mathrm{E}_{\mathrm{a}} / \mathrm{RT}\right)$ and $\mathrm{k}=\mathrm{AT}{ }^{\mathrm{n}} \exp \left(-\mathrm{E}_{\mathrm{a}} / \mathrm{RT}\right)$. The units of the rate coefficients are $\mathrm{s}^{-1}$ and $\mathrm{cm}^{3} \mathrm{~mol}^{-1} \mathrm{~s}^{-1}$ for first and second order reactions, respectively. The units for the activation barrier are $\mathrm{kcal} \mathrm{mol}^{-1}$. 
activation energies are given in $\mathrm{kcal} \mathrm{mol}^{-1}$. Kinetic simulations were carried out at experimentally determined temperatures and reaction times. All simulations were carried out using IBM's chemical kinetic simulator. ${ }^{44}$ The agreement between the simulated concentrations and the experimentally determined concentrations of TMS and the major products viz. $\mathrm{CH}_{4}$ and $\mathrm{C}_{2} \mathrm{H}_{4}$ is very good. In case of minor products $\mathrm{C}_{2} \mathrm{H}_{6}$ and $\mathrm{C}_{3} \mathrm{H}_{6}$, the agreement seems to be reasonably good. It should be noted here that, the maximum concentrations of these minor products are less than $2 \%$ in the temperature range used in this study.

The reaction mechanism suggested ${ }^{19,20}$ in the previous studies for decomposition of TMS was confined to lower temperatures (840-1055 K). However, kinetic simulations were not carried out in their studies to reproduce experimental concentrations of reactant and products. In the present work, detailed chemical kinetic mechanism for TMS decomposition was proposed. The present reaction scheme was able to simulate the experimental concentrations of reactant and products in the temperature range of 1058-1194 K. The proposed mechanism in the present studies explains the formation of all the products quantitatively.

3.1a Methane: The formation of $\mathrm{CH}_{4}$ from the reactant TMS can be explained by the formation of $\mathrm{CH}_{3}$ radicals and trimethylsilyl radicals $\left(\left(\mathrm{CH}_{3}\right)_{3} \mathrm{Si}\right)$ via $\mathrm{Si}-$ $\mathrm{C}$ bond cleavage. Each of these two radicals $\mathrm{CH}_{3}$ and $\left(\mathrm{CH}_{3}\right)_{3} \mathrm{Si}$ further participate in secondary reactions via abstraction, recombination and dissociation reactions. The competition between these three classes of elementary reactions determines the concentrations of all the reaction products in the decomposition of TMS. The $\left(\mathrm{CH}_{3}\right)_{3} \mathrm{Si}$, and $\left(\mathrm{CH}_{3}\right)_{2} \mathrm{Si}$ radicals further undergo decomposition through $\mathrm{Si}-\mathrm{C}$ bond cleavage to produce $\mathrm{CH}_{3}$ radicals, dimethylsilyl $\left(\left(\mathrm{CH}_{3}\right)_{2} \mathrm{Si}\right)$ and methylsilyl $\left(\left(\mathrm{CH}_{3}\right) \mathrm{Si}\right)$ radicals respectively.

$$
\begin{aligned}
\left(\mathrm{CH}_{3}\right)_{4} \mathrm{Si} & \rightarrow \mathrm{CH}_{3}+\left(\mathrm{CH}_{3}\right)_{3} \mathrm{Si} k_{1} \\
& =4.36 \times 10^{14} \exp (-61.98 / \mathrm{RT}) \mathrm{s}^{-1} \\
\left(\mathrm{CH}_{3}\right)_{3} \mathrm{Si} & \rightarrow\left(\mathrm{CH}_{3}\right)_{2} \mathrm{Si}+\mathrm{CH}_{3} \mathrm{k}_{5} \\
& =1.00 \times 10^{15} \exp (-52.80 / \mathrm{RT}) \mathrm{s}^{-1}
\end{aligned}
$$

Studies by Clifford et al., ${ }^{19}$ and Baldwin et al.,${ }^{20}$ show that the first order rate coefficient for the formation of methane at high temperatures is a non-chain process and rate coefficient is determined by reaction $\mathrm{R} 1$. The $\mathrm{CH}_{3}$ radicals thus formed in turn abstract any one of the $\mathrm{H}$ atom present in any one of the $\mathrm{CH}_{3}$ groups in TMSin the reaction mixture to produce $\mathrm{CH}_{4}$. Thekinetic parameters for this reactionwere reported by Baldwin et al. ${ }^{20}$

$$
\begin{aligned}
\mathrm{CH}_{3} & +\left(\mathrm{CH}_{3}\right)_{4} \mathrm{Si} \rightarrow \mathrm{CH}_{4} \\
& +\left(\mathrm{CH}_{3}\right)_{3} \mathrm{SiCH}_{2} \mathrm{k}_{2}=1.99 \times 10^{11} \\
& \exp (-9.60 / \mathrm{RT}) \mathrm{cm}^{3} \mathrm{~mol}^{-1} \mathrm{~s}^{-1}
\end{aligned}
$$

The reaction between $\mathrm{CH}_{3}$ and $\mathrm{C}_{2} \mathrm{H}_{6}$ to form $\mathrm{CH}_{4}$ cannot be ruled out and therefore a reaction $\mathrm{R} 11$ to this effect is added to the scheme.

$$
\begin{aligned}
\mathrm{C}_{2} \mathrm{H}_{6}+\mathrm{CH}_{3} \rightarrow & \mathrm{C}_{2} \mathrm{H}_{5}+\mathrm{CH}_{4} k_{11}=3.02 \times 10^{12} \\
& \exp (-13.59 / \mathrm{RT}) \mathrm{cm}^{3} \mathrm{~mol}^{-1} \mathrm{~s}^{-1}
\end{aligned}
$$

Although dissociation of methane in the studied temperature range is negligible, we cannot rule out the formation of $\mathrm{CH}_{3}$ radicals via $\mathrm{CH}_{4}$ dissociation. Therefore, a reaction $\mathrm{R} 17$ is added in the reaction scheme.

$\mathrm{CH}_{4} \rightarrow \mathrm{CH}_{3}+\mathrm{H} k_{17}=7.80 \times 10^{14} \exp (-103.83 / \mathrm{RT}) \mathrm{s}^{-1}$

It is obvious that R17 is highly insensitive and it is also reflected in the sensitivity analysis. Loss of $\mathrm{CH}_{4}$ via its reaction with $\mathrm{H}$ atom (R28 and $\mathrm{R} 30)$ are also included in the proposed reaction scheme for completeness.

$$
\begin{aligned}
\mathrm{CH}_{4}+\mathrm{H} \rightarrow & \mathrm{CH}_{3}+\mathrm{H}_{2} k_{28}=1.77 \times 10^{14} \\
& \exp (-13.78 / \mathrm{RT}) \mathrm{cm}^{3} \mathrm{~mol}^{-1} \mathrm{~s}^{-1} \\
\mathrm{CH}_{4}+\mathrm{H} \rightarrow & \mathrm{CH}_{3}+2 \mathrm{H} k_{30}=0.44 \times 10^{1} \\
& \exp (-7.88 / \mathrm{RT}) \mathrm{cm}^{3} \mathrm{~mol}^{-1} \mathrm{~s}^{-1}
\end{aligned}
$$

The sensitivity of each reaction towards the formation and decomposition of $\mathrm{CH}_{4}$ was carried out by varying the rate coefficients of each reaction by a factor of 10. The results are shown in figure 8 in terms of percentage change in the concentrations with respect to the reaction numbers. It is obvious from this Figure that the reactions $\mathrm{R} 1$ and $\mathrm{R} 5$ are very sensitive to the formation of $\mathrm{CH}_{4}$. In both these reaction paths $\mathrm{CH}_{3}$ radical is formed which is the key species for the decomposition of TMS. Reactions R12, R13, R30 and R38 have shown significant influence on the formation of methane.

3.1b Ethylene: The other major product is ethylene, which is formed mainly via decomposition of ethyl radical $\left(\mathrm{C}_{2} \mathrm{H}_{5}\right)$. Concentrations of $\mathrm{C}_{2} \mathrm{H}_{4}$ were found to be higher than the concentrations of $\mathrm{CH}_{4}$ by $10 \%$ in the studied temperature range. The major source for the formation of $\mathrm{C}_{2} \mathrm{H}_{5}$ radical is the self-reaction of $\mathrm{CH}_{3}$ radicals $(\mathrm{R} 8)$.

$$
\begin{aligned}
\mathrm{CH}_{3}+\mathrm{CH}_{3} \rightarrow & \mathrm{C}_{2} \mathrm{H}_{5}+\mathrm{H} k_{8} 2.40 \times 10^{13} \\
& \exp (-12.88 / \mathrm{RT}) \mathrm{cm}^{3} \mathrm{~mol}^{-1} \mathrm{~s}^{-1}
\end{aligned}
$$




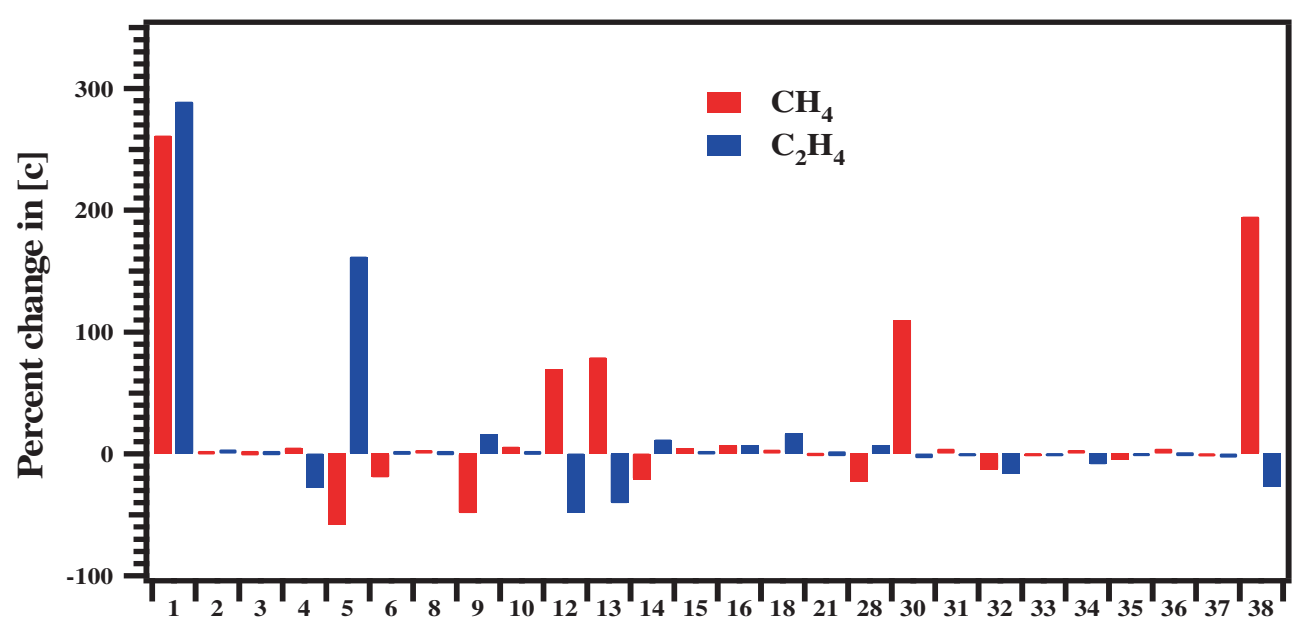

Reaction number

Figure 8. Sensitivity analysis of the proposed reaction scheme carried out at $1141 \mathrm{~K}$ for the formation of methane and ethylene. The rate coefficients were varied by a factor of 10 to see the sensitivity of each reaction for the formation of methane and ethylene.

It should also be noted here that the self-reaction of $\mathrm{CH}_{3}$ radical also form $\mathrm{C}_{2} \mathrm{H}_{4}$ directly (R9).

$$
\begin{aligned}
\mathrm{CH}_{3}+\mathrm{CH}_{3} \rightarrow & \mathrm{C}_{2} \mathrm{H}_{4}+\mathrm{H}_{2} k_{9}=9.90 \times 10^{15} \\
& \exp (-32.98 / \mathrm{RT}) \mathrm{cm}^{3} \mathrm{~mol}^{-1} \mathrm{~s}^{-1}
\end{aligned}
$$

$\mathrm{C}_{2} \mathrm{H}_{4}$ is also formed via the reaction of $\mathrm{C}_{2} \mathrm{H}_{5}$ with $\mathrm{H}$ atom (R10) in the decomposition of TMS.

$$
\mathrm{C}_{2} \mathrm{H}_{5}+\mathrm{H} \rightarrow \mathrm{C}_{2} \mathrm{H}_{4}+\mathrm{H}_{2} k_{10}=1.81 \times 10^{14} \mathrm{~cm}^{3} \mathrm{~mol}^{-1} \mathrm{~s}^{-1}
$$

The $\mathrm{C}_{2} \mathrm{H}_{5}$ radical undergo unimolecular decomposition (R12) to form $\mathrm{C}_{2} \mathrm{H}_{4}$ and $\mathrm{H}$ atoms. The reaction of $\mathrm{C}_{2} \mathrm{H}_{5}$ radical with another $\mathrm{C}_{2} \mathrm{H}_{5}$ radical (R13) leads to the formation of $\mathrm{C}_{2} \mathrm{H}_{4}$, in addition to $\mathrm{C}_{2} \mathrm{H}_{6}$. These reactions are the major contributors to the formation of $\mathrm{C}_{2} \mathrm{H}_{4}$.

$$
\begin{aligned}
\mathrm{C}_{2} \mathrm{H}_{5} & \rightarrow \mathrm{C}_{2} \mathrm{H}_{4}+\mathrm{Hk}_{12} \\
= & 3.06 \times 10^{10}(\mathrm{~T})^{0.95} \exp (-36.94 / \mathrm{RT}) \mathrm{s}^{-1}(\mathrm{R} 12) \\
\mathrm{C}_{2} \mathrm{H}_{5}+\mathrm{C}_{2} \mathrm{H}_{5} & \rightarrow \mathrm{C}_{2} \mathrm{H}_{4}+\mathrm{C}_{2} \mathrm{H}_{6} k_{13} \\
& =1.45 \times 10^{12} \mathrm{~cm}^{3} \mathrm{~mol}^{-1} \mathrm{~s}^{-1}
\end{aligned}
$$

As propylene is one of the minor products, formation of $\mathrm{C}_{2} \mathrm{H}_{3}$ radical (R19) is included in the reaction scheme. Also, a bimolecular reaction of $\mathrm{CH}_{3}$ with the buffer gas (Ar) will lead to the formation of $\mathrm{CH}_{2}$ (carbene) intermediate and this reaction is included in the reaction scheme. The $\mathrm{C}_{2} \mathrm{H}_{3}$ radical further reacts with $\mathrm{H}_{2}$ (R21) and $\mathrm{CH}_{2}$ (R24) to form $\mathrm{C}_{2} \mathrm{H}_{4}$ and these two reactions are the minor contributors to the formation of $\mathrm{C}_{2} \mathrm{H}_{4}$.

$$
\begin{aligned}
\mathrm{C}_{2} \mathrm{H}_{3}+\mathrm{H}_{2} \rightarrow & \mathrm{C}_{2} \mathrm{H}_{4}+\mathrm{H} k_{21}=2.04 \times 10^{14}(\mathrm{~T})^{2.56} \\
& \exp (-5.03 / \mathrm{RT}) \mathrm{cm}^{3} \mathrm{~mol}^{-1} \mathrm{~s}^{-1}(\mathrm{R} 21)
\end{aligned}
$$

$$
\mathrm{CH}_{3}+\mathrm{CH}_{2} \rightarrow \mathrm{C}_{2} \mathrm{H}_{4}+\mathrm{H} k_{24}=6.02 \times 10^{13} \mathrm{~cm}^{3} \mathrm{~mol}^{-1} \mathrm{~s}^{-1}
$$

Propylene reacts with $\mathrm{H}$ atoms to form both $\mathrm{n}-\mathrm{C}_{3} \mathrm{H}_{7}$ and iso- $\mathrm{C}_{3} \mathrm{H}_{7}$ radicals (R37 \& R38), respectively. These two radicals further decompose (R34 \& R36) to give $\mathrm{C}_{2} \mathrm{H}_{4}$. As the concentrations of both propylene and the subsequently formed radicals are minimum in the decomposition reaction of TMS, the contributions of these reactions may be negligible.

$$
\begin{aligned}
\text { iso- } \mathrm{C}_{3} \mathrm{H}_{7} & \rightarrow \mathrm{C}_{2} \mathrm{H}_{4}+\mathrm{CH}_{3} k_{34} \\
& =1.00 \times 10^{12} \exp (-34.58 / \mathrm{RT}) \mathrm{s}^{-1}(\mathrm{R} 34) \\
\mathrm{n}_{-} \mathrm{C}_{3} \mathrm{H}_{7} & \rightarrow \mathrm{C}_{2} \mathrm{H}_{4}+\mathrm{CH}_{3} k_{36} \\
& =2.70 \times 10^{13} \exp (-30.04 / \mathrm{RT}) s^{-1} \quad(\mathrm{R} 36)
\end{aligned}
$$

The sensitivity analysis of the proposed reaction scheme is carried out for the formation of $\mathrm{C}_{2} \mathrm{H}_{4}$ and the results are shown in figure 8. Reactions $\mathrm{R} 1$ and $\mathrm{R} 5$ are very sensitive for the formation of $\mathrm{C}_{2} \mathrm{H}_{4}$ as the formation of $\mathrm{CH}_{3}$ radicals governs the formation of $\mathrm{C}_{2} \mathrm{H}_{5}$ radicals. Two more reactions which have shown influence on the formation of $\mathrm{C}_{2} \mathrm{H}_{4}$ are R12 and R13.

3.1c Minor products: The minor reaction products observed in the experiments are ethane $\left(\mathrm{C}_{2} \mathrm{H}_{6}\right)$ and propylene $\left(\mathrm{C}_{3} \mathrm{H}_{6}\right)$. The concentrations of these two products are less than $2 \%$, when compared with the main products. The concentration of $\mathrm{C}_{2} \mathrm{H}_{6}$ was observed to be increasing upto $1120 \mathrm{~K}$ and beyond this temperature the concentrations of $\mathrm{C}_{2} \mathrm{H}_{6}$ were found to be decreasing. The major channel for the formation of $\mathrm{C}_{2} \mathrm{H}_{6}$ is the recombination of two $\mathrm{CH}_{3}$ radicals (R6).

$$
\begin{aligned}
\mathrm{CH}_{3}+\mathrm{CH}_{3} \rightarrow & \mathrm{C}_{2} \mathrm{H}_{6} k_{6}=4.47 \times 10^{13}(\mathrm{~T})^{-0.69} \\
& \exp (-0.17 / \mathrm{RT}) \mathrm{cm}^{3} \mathrm{~mol}^{-1} \mathrm{~s}^{-1}
\end{aligned}
$$


The minor channels for the formation of ethane include the abstraction of $\mathrm{H}$ atom by $\mathrm{CH}_{3}$ radical from methane (R18), $\mathrm{H}$ atom abstraction reaction by $\mathrm{C}_{2} \mathrm{H}_{5}$ radical from ethylene (R29) and from propylene radical (R31), and the reaction of $\mathrm{C}_{2} \mathrm{H}_{5}$ radical with $\mathrm{H}$ atom (R20).

$$
\begin{aligned}
\mathrm{CH}_{4}+\mathrm{CH}_{3} \rightarrow & \mathrm{C}_{2} \mathrm{H}_{6}+\mathrm{H} k_{18}=2.98 \times 10^{11}(\mathrm{~T})^{1.00} \\
& \exp (-44.91 / \mathrm{RT}) \mathrm{cm}^{3} \mathrm{~mol}^{-1} \mathrm{~s}^{-1}(\mathrm{R} 18) \\
\mathrm{C}_{2} \mathrm{H}_{5}+\mathrm{H} \rightarrow \mathrm{C}_{2} \mathrm{H}_{6} k_{20}=4.50 \times 10^{13} \mathrm{~cm}^{3} \mathrm{~mol}^{-1} \mathrm{~s}^{-1}(\mathrm{R} 20) & \\
\mathrm{C}_{2} \mathrm{H}_{4}+\mathrm{C}_{2} \mathrm{H}_{5} \rightarrow & \mathrm{C}_{2} \mathrm{H}_{6}+\mathrm{C}_{2} \mathrm{H}_{3} k_{29}=1.58 \times 10^{11} \\
& \exp (-14.86 / \mathrm{RT}) \mathrm{cm}^{3} \mathrm{~mol}^{-1} \mathrm{~s}^{-1}(\mathrm{R} 29) \\
\mathrm{C}_{2} \mathrm{H}_{5}+\mathrm{C}_{3} \mathrm{H}_{6} \rightarrow & \mathrm{C}_{2} \mathrm{H}_{6}+\mathrm{n}-\mathrm{C}_{3} \mathrm{H}_{5} k_{31}=6.92 \times 10^{10} \\
& \exp (-5.19 / \mathrm{RT}) \mathrm{cm}^{3} \mathrm{~mol}^{-1} \mathrm{~s}^{-1}(\mathrm{R} 31)
\end{aligned}
$$

The contribution of reactions of $\mathrm{C}_{2} \mathrm{H}_{5}$ radicals with both $\mathrm{n}-\mathrm{C}_{3} \mathrm{H}_{7}$ and iso- $\mathrm{C}_{3} \mathrm{H}_{7}$ (R37 \& R35) radicals was observed to be negligibly small during the simulations.

$$
\text { iso- } \begin{aligned}
\mathrm{C}_{3} \mathrm{H}_{7}+\mathrm{C}_{2} \mathrm{H}_{5} & \rightarrow \mathrm{C}_{2} \mathrm{H}_{6}+\mathrm{C}_{3} \mathrm{H}_{6} k_{35} \\
& =3.13 \times 10^{10}(\mathrm{~T})^{-0.35} \mathrm{~cm}^{3} \mathrm{~mol}^{-1} \mathrm{~s}^{-1}
\end{aligned}
$$

$$
\begin{aligned}
\mathrm{n}-\mathrm{C}_{3} \mathrm{H}_{7}+\mathrm{C}_{2} \mathrm{H}_{5} & \rightarrow \mathrm{C}_{2} \mathrm{H}_{6}+\mathrm{C}_{3} \mathrm{H}_{6} k_{37} \\
& =1.45 \times 10^{12} \mathrm{~cm}^{3} \mathrm{~mol}^{-1} \mathrm{~s}^{-1}
\end{aligned}
$$

The contribution of the reactions $\mathrm{R} 6$ and R18 depends on the availability of $\mathrm{CH}_{3}$ radicals. It is obvious from the proposed scheme that $\mathrm{CH}_{3}$ radicals are involved in many other reactions. Therefore, the availability of $\mathrm{CH}_{3}$ radicals depends on the rates of other reactions. The concentrations of ethane formed in the simulations using the proposed scheme are in good agreement with experimentally measured concentrations.

Propylene is another minor product obtained in the experiments with a maximum concentration of $1 \%$. Its formation is included in the reaction scheme by adding the reaction of $\mathrm{CH}_{3}$ radicals with one of the major product, ethylene.

$$
\begin{aligned}
\mathrm{C}_{2} \mathrm{H}_{4}+\mathrm{CH}_{3} \rightarrow & \mathrm{C}_{3} \mathrm{H}_{6}+\mathrm{H} k_{15}=2.0 \times 10^{13} \\
& \exp \left(-10.00 \mathrm{kcal} \mathrm{mol}^{-1} / \mathrm{RT}\right) \mathrm{cm}^{3} \mathrm{~mol}^{-1} \mathrm{~s}^{-1}
\end{aligned}
$$

Another reaction in which $\mathrm{C}_{3} \mathrm{H}_{6}$ is formed is the reaction of $\mathrm{C}_{2} \mathrm{H}_{5}$ radicals with both $\mathrm{n}-\mathrm{C}_{3} \mathrm{H}_{7}$ and iso- $\mathrm{C}_{3} \mathrm{H}_{7}$ radicals ( $\mathrm{R} 37$ \& $\mathrm{R} 35)$. As described earlier, the concentrations of $n-\mathrm{C}_{3} \mathrm{H}_{7}$ and iso- $\mathrm{C}_{3} \mathrm{H}_{7}$ radicals are very insignificant, these two reactions would not show any significant contribution in the formation of propylene. The propylene thus formed is consumed in its reactions with $\mathrm{CH}_{3}$ radicals (R16) and $\mathrm{H}$ atom (R32 and $\mathrm{R} 33$ ). Propylene undergoes $\mathrm{C}-\mathrm{C}$ bond scission in the studied temperature range to form $\mathrm{CH}_{3}$ radicals. Therefore, reaction $\mathrm{R} 19$ is added in the proposed scheme.

$$
\begin{aligned}
\mathrm{C}_{3} \mathrm{H}_{6}+\mathrm{H} \rightarrow & \mathrm{C}_{2} \mathrm{H}_{4}+\mathrm{CH}_{3} k_{16}=1.32 \times 10^{12}(\mathrm{~T})^{1.50} \\
& \exp (-2.01 / \mathrm{RT}) \mathrm{cm}^{3} \mathrm{~mol}^{-1} \mathrm{~s}^{-1} \quad(\mathrm{R} 16)
\end{aligned}
$$

$$
\mathrm{C}_{3} \mathrm{H}_{6} \rightarrow \mathrm{CH}_{3}+\mathrm{C}_{2} \mathrm{H}_{3} k_{19}=8.00 \times 10^{14} \exp (-88.03 / \mathrm{RT}) \mathrm{s}^{-1}
$$

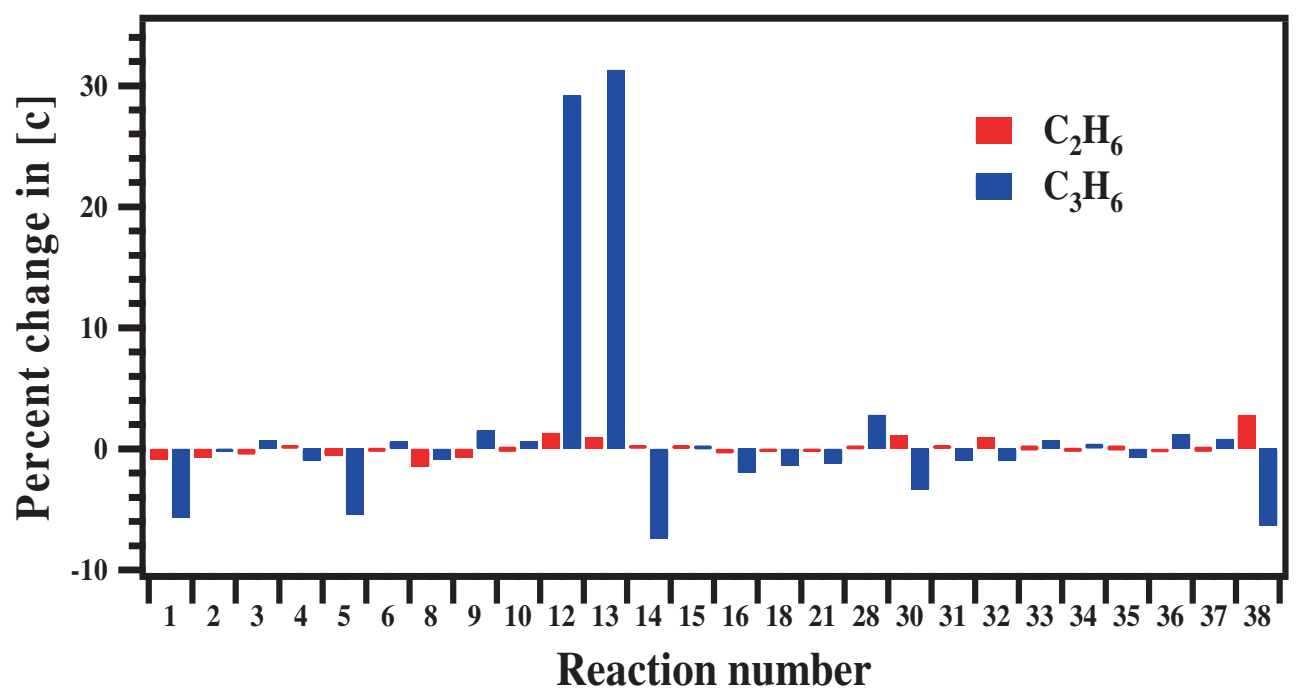

Figure 9. Sensitivity analysis of the proposed reaction scheme carried out at $1141 \mathrm{~K}$ for the formation of ethane and propylene. The rate coefficients were varied by a factor of 10 to see the sensitivity of each reaction for the formation of ethane and propylene. 


$$
\begin{aligned}
\mathrm{C}_{3} \mathrm{H}_{6}+\mathrm{H} \rightarrow & \mathrm{n}-\mathrm{C}_{3} \mathrm{H}_{7} k_{32}=2.50 \times 10^{11}(\mathrm{~T})^{0.51} \\
& \exp (-2.62 / \mathrm{RT}) \mathrm{cm}^{3} \mathrm{~mol}^{-1} \mathrm{~s}^{-1} \\
\mathrm{C}_{3} \mathrm{H}_{6}+\mathrm{H} \rightarrow & \text { iso- } \mathrm{C}_{3} \mathrm{H}_{7} k_{33}=4.24 \times 10^{11}(\mathrm{~T})^{0.51} \\
& \exp (-1.23 / \mathrm{RT}) \mathrm{cm}^{3} \mathrm{~mol}^{-1} \mathrm{~s}^{-1}
\end{aligned}
$$

The concentrations of propylene predicted using the proposed reaction scheme is in reasonably good agreement with the experimentally measured concentrations of propylene.

The sensitivity analyses of the proposed reactions for the formation of both the minor products namely ethane and propylene were carried out and are shown in figure 9 . No reaction was found to be significantly sensitive in case of either the formation or decomposition of ethane. However, in case of propylene, reactions R12 and $\mathrm{R} 13$ were found to be very sensitive. In both these reactions, the $\mathrm{C}_{2} \mathrm{H}_{5}$ radical is consumed. Therefore, it is obvious that the formation of propylene is governed by the available concentrations of $\mathrm{C}_{2} \mathrm{H}_{5}$ radicals.

Another very important product that we could not measure in the experiments is $\mathrm{H}_{2}$. Both GC-FID and IR techniques are not suitable to identify this product. However, the proposed reaction scheme has predicted formation of significant amount of $\mathrm{H}_{2}$. The contribution for the formation of $\mathrm{H}_{2}$ is significant via the reactions

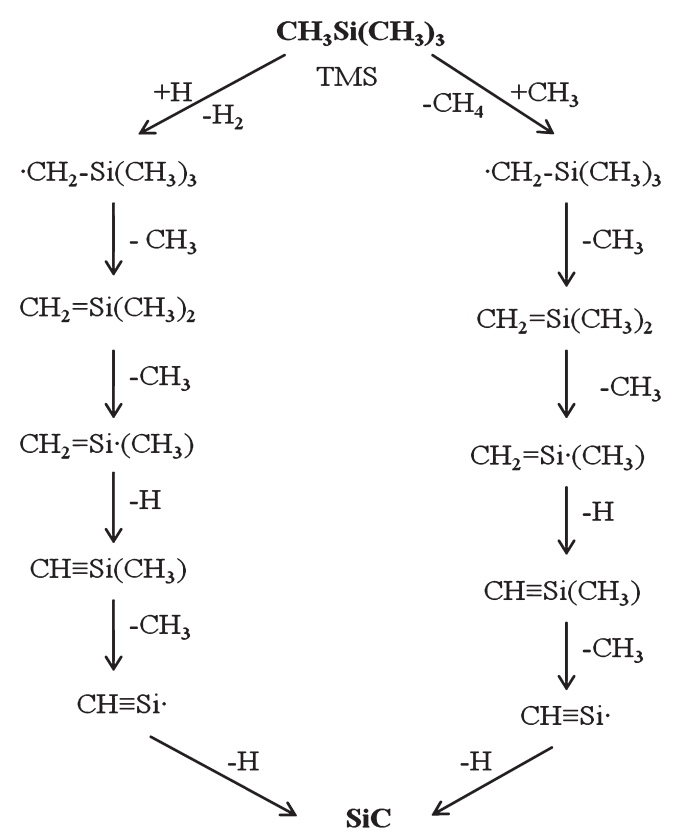

Figure 10. Suggested pathways for the formation of $\mathrm{SiC}$ during the thermal decomposition of TMS in single pulse shock tube experiments.
R23 and R28, because the concentrations of $\mathrm{CH}_{3}$ and TMS are high when compared to other radicals.

$$
\begin{aligned}
\left(\mathrm{CH}_{3}\right)_{4} \mathrm{Si}+\mathrm{H} \rightarrow & \mathrm{H}_{2}+\left(\mathrm{CH}_{3}\right)_{3} \mathrm{SiCH}_{2} k_{4} \\
= & 4.71 \times 10^{5}(\mathrm{~T})^{2.65} \\
& \exp (-4.88 / \mathrm{RT}) \mathrm{cm}^{3} \mathrm{~mol}^{-1} \mathrm{~s}^{-1}(\mathrm{R} 4) \\
\mathrm{CH}_{3}+\mathrm{H} \rightarrow & \mathrm{CH}_{2}+\mathrm{H}_{2} k_{23}=6.02 \times 10^{13} \\
& \exp (-15.10 / \mathrm{RT}) \mathrm{cm}^{3} \mathrm{~mol}^{-1} \mathrm{~s}^{-1}(\mathrm{R} 23) \\
\mathrm{CH}_{2}+\mathrm{H} \rightarrow & \mathrm{CH}+\mathrm{H}_{2} k_{25}=1.63 \times 10^{14} \mathrm{~cm}^{3} \mathrm{~mol}^{-1} \mathrm{~s}^{-1} \\
\mathrm{CH}_{3}+\mathrm{Ar} \rightarrow & \mathrm{CH}+\mathrm{H}_{2}+\mathrm{Ark}_{27}=6.90 \times 10^{14} \\
& \exp (-82.50 / R T) \mathrm{cm}^{3} \mathrm{~mol}^{-1} \mathrm{~s}^{-1}(\mathrm{R} 27) \\
\mathrm{CH}_{4}+\mathrm{H} \rightarrow & \mathrm{CH} \mathrm{H}_{3}+\mathrm{H}_{2} k_{28}=1.77 \times 10^{14} \\
& \exp (-13.78 / \mathrm{RT}) \mathrm{cm}^{3} \mathrm{~mol}^{-1} \mathrm{~s}^{-1}(\mathrm{R} 28)
\end{aligned}
$$

As the concentration of hydrogen $\left(\mathrm{H}_{2}\right)$ is significant, we have included the decomposition of $\mathrm{H}_{2}$ as well to generate the $\mathrm{H}$ atoms in the reaction.

$$
\begin{aligned}
\mathrm{H}_{2}+\mathrm{Ar} \rightarrow & \mathrm{H}+\mathrm{H}+\mathrm{Ark}_{14}=5.33 \times 10^{14} \\
& \exp (-96.01 / \mathrm{RT}) \mathrm{cm}^{3} \mathrm{~mol}^{-1} \mathrm{~s}^{-1}(\mathrm{R} 14)
\end{aligned}
$$

Overall, the concentrations of all the products obtained in the simulations are found to be in good

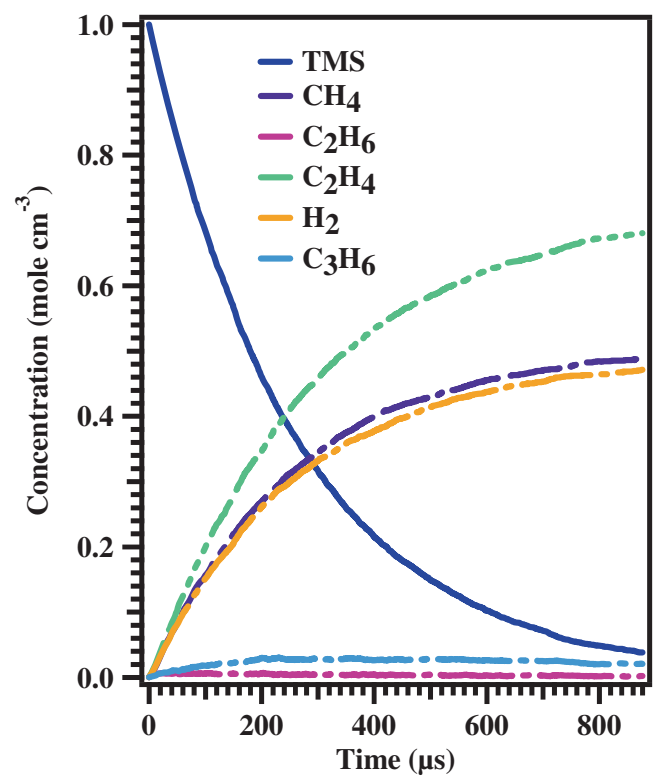

Figure 11. The distribution of concentrations of TMS and various products with respect to time when simulations were carried out using the proposed reaction scheme with the reaction time of $880 \mu \mathrm{s}$ and the experimental temperature of $1194 \mathrm{~K}$. 
agreement with the experimentally measured concentrations.

Hydrogen atom and methyl radical are reactive intermediates in pyrolysis of TMS at high temperatures. These two species are responsible for the formation of $\mathrm{SiC}$, probably through the following reaction mechanism. In the present work, the formation of $\mathrm{SiC}$ and their growth was not focused. The main aim of this study is to monitor the products formed from decomposition of TMS and their gas phase contributions to the total reaction (figure 10).

The concentration vs time profiles of reactant and the products obtained in the simulations by using the proposed reaction scheme, with the reaction time of $880 \mu \mathrm{s}$ and at experimental temperature of $1194 \mathrm{~K}$ is shown in figure 11. This profile shows once again the major and minor products in the thermal decomposition of TMS in the studied temperature range of 1058-1194 K.

\section{Conclusions}

The pyrolysis of TMS in the temperature range of 1058-1194 K was investigated, using a SPST. The main reaction products in the experiments are found to be methane and ethylene; and the minor reaction products are ethane and propylene respectively. The obtained rate coefficient for the total decomposition of TMS in the lower temperature range is $\mathrm{k}_{\text {total }}$ $(1058-1130 \mathrm{~K})=(4.61 \pm 0.70) \times 10^{18} \exp (-(79.9 \mathrm{kcal}$ $\left.\left.\mathrm{mol}^{-1} \pm 3.5\right) / \mathrm{RT}\right) \mathrm{s}^{-1}$, and at high temperature range is, $\mathrm{k}_{\text {total }}(1130-1194 \mathrm{~K})=(1.33 \pm 0.19) \times 10^{6} \exp$ $\left(-\left(15.3 \mathrm{kcal} \mathrm{mol}^{-1} \pm 3.5\right) / \mathrm{RT}\right) \mathrm{s}^{-1}$. The rate coefficient obtained for the formation of methane in the studied temperature range is $k_{\text {methane }}(1058-1194 \mathrm{~K})=(4.36 \pm$ $1.23) \times 10^{14} \exp \left(-\left(61.9 \mathrm{kcal} \mathrm{mol}^{-1} \pm 4.9\right) / \mathrm{RT}\right) \mathrm{s}^{-1}$ where $\mathrm{R}$ is expressed in the units of $\mathrm{kcal} \mathrm{K}^{-1} \mathrm{~mol}^{-1}$. The decomposition mechanism is proposed using 21 species and 38 elementary reactions. The concentration profiles of all the products obtained using the proposed scheme is observed to be in good agreement with the experimental findings. The C-Si bond scission is the governing reaction pathway in the complete decomposition of TMS in the temperature range of 1058-1194 K.

\section{Acknowledgments}

B.R. thanks Council of Scientific and Industrial Research (CSIR), Government of India for funding. A.P. is very grateful to CSIR for providing a research fellowship. A.P. also thank Mr. G. Sudhakar and Mr. M. Balaganesh for fruitful discussions and their help.

\section{References}

1. Herlin N, Lefebvre M, Pealat M and Perrin J 1992 J. Phys. Chem. 967063

2. Chaussende D, Ucar M, Auvray L, Baillet F, Pons M and Madar R 2005 Cryst. Growth Des. 51539

3. Muller S G, Brady M F, Burk A A, Hobgood H M, Jenny J R, Leonard R T, Malta D P, Powell A R, Sumakeris J J, Tsvetkov V F and Carter C H 2006 Superattices Microstruct. 40195

4. Powell J A, Matus L G, Harris G L and Yang C Y W 1989 In Amorphous and Crystalline Silicon Carbide Springer Proceedings in Physics Vol. 34 (Berlin: Springer)

5. Golecki I, Reidinger F and Marti J 1992 Appl. Phys. Lett. 601703

6. Avigal Y, Schieber M and Levin R 1974 J. Cryst. Growth 24/25 188

7. Chappell M J and Millman R S 1974 J. Mater. Sci. 9 1933

8. Nam D H, Kim B G, Yoon J Y, Lee M H, Seo W S, Jeong S M, Yang C W and Lee W J 2014 Cryst. Growth Des. 145569

9. Seo Y H, Nahma K S, Suh E K, Lee H J and Hwang Y G J 1997 Vac. Sci. Technol. A 152226

10. Herlin N, Lefebvre M, Pealat M and Perrin J $1992 \mathrm{~J}$. Phys. Chem. 967063

11. Avigal Y and Schieber M 1971 J. Cryst. Growth 9127

12. Figueras R A, Garelik S, Santiso J, RodroguezClemente R, Armas B, Combescure Berjoan C, Saurel J M and Caplain R 1992 Mater. Sci. Eng. B 1183

13. Seong-Min J, Kyung-Hun K, Young J Y, Myung-Hyun $\mathrm{L}$ and Won-Seon S 2012 J. Cryst. Growth 35748

14. Schalla R L, McDonald G E and Gerstein M 1955 Symp. (Int.) Combust. 5705

15. Gerhold B W and Inkrott K E 2006 Combust. Flame 146 407

16. Cullis C F, Herron D and Hirschler M M 1985 Combust. Flame $\mathbf{5 9} 151$

17. Wrobel A M, Czeremuszkin G, Szymanowski H and Kowalski J 1990 Plasma Chem. Plasma Process. 10277

18. Helm D F and Mack E 1937 J. Am. Chem. Soc. 5960

19. Clifford R P, Gowenlock B G, Johnson C A F and Stevenson J 1972 J. Organomet. Chem. 3453

20. Baldwin A C, Davidson I M T and Reed M D $1978 \mathrm{~J}$. Chem. Soc., Faraday Trans. 1742171

21. Taylor J E and Milazzo T S 1978 J. Phys. Chem. 82847

22. Doncaster A M and Walsh R 1976 J. Chem. Soc., Faraday Trans. $\mathbf{7 2} 2908$

23. Tschuikow-Roux E 1965 Phys. Fluids 8821

24. Tschuikow-Roux E, Sirnrnie J M and Quirring W J 1970 Astronaut. Acta 15511

25. Lifshitz A, Bauer A H and Resler E L 1963 J. Chem. Phys. 382056

26. Rajakumar B, Reddy K P J and Arunan E 2002 J. Phys. Chem. A 1068366

27. Gaydon A G and Hurle I R 1963 In The shock tube in high temperature chemical physics (New York: Reinhold Publishing)

28. ShockWaves@Marseille I: Hypersonics, Shock Tube \& Shock Tunnel Flow R Brun and L Z Dumitrescu 1995 (Eds.) (Berlin: Springer-Verlag)

29. Bershader D and Hanson R 1987 Astrophys. Space Sci. 138426 
30. Mirels H 1964 AIAA Journal 284

31. Li S, Ren W, Davidson D F and Hanson R K 2012 In Boundary Layer Effects behind Incident and Reflected Shock Waves in a Shock Tube 28th International Symposium on Shock Waves (Berlin: Springer) Vol. 2 p. 471

32. Lifshitz A, Tamburu C, Suslensky A and Dubnikova F 2006 J. Phys. Chem. A 11011677

33. Manion J A and Awan I A 2013 Proc. Combust. Inst. 34 537

34. Herzler J, Manion J A and Tsang W 1997 J. Phys. Chem. A 1015500

35. Rosado-Reyes C M and Tsang W 2012 J. Phys. Chem. A 1169599

36. Stranic I, Davidson D F and Hanson R K 2013 Chem. Phys. Lett. 58418

37. Skinner G B and Sokoloski E M 1960 J. Phys. Chem. 64 1028

38. Hidaka Y, Higashihara T, Ninomiya N, Masaoka H, Nakamura T and Kawano H 1996 Int. J. Chem. Kinet. 28137

39. Lifshitz A, Tamburu C, Suslensky A and Dubnikova F 2004 J. Phys. Chem. A 1083430

40. Tsang W 1965 J. Chem. Phys. 444283

41. Taylor J E, Hutchings D A and Frech K J 1969 J. Am. Chem. Soc. 912215

42. Sivaramakrishnan R, Michael J V, Harding L B and Klippenstein S J 2012 J. Phys. Chem. A 1165981

43. Pacey P D 1973 Can. J. Chem. 512415

44. Chemical Kinetics Simulator 1.0. 1995 IBM Almaden research center, IBM Corporation

45. Berkley R E, Safarik I, Gunning H E and Strausz O P 1973 J. Phys. Chem. 771734

46. Oueslati I, Kerkeni B, Spielfiedel A, Tchang-Brillet W and Feautrier N 2014 J. Phys. Chem. A 1181089

47. Wang B S, Hou H, Yoder L M, Muckerman J T and Fockenberg C 2003 J. Phys. Chem. A 10711414

48. Davidson D F, Di Rosa M D, Chang E J, Hanson R K and Bowman C T 1995 Int. J. Chem. Kinet. 271179

49. Kern R D, Singh H J and Wu C H 1988 Int. J. Chem. Kinet. 20731
50. Lifshitz A, Tamburu C and Suslensky A 1990 J. Phys. Chem. 942966

51. Yampolskii Y P and Rybin V M 1973 React. Kinet. Catal. Lett. 1321

52. Curran H J 2006 Int. J. Chem. Kinet. 38250

53. Baulch D L, Cobos C J, Cox R A, Esser C, Frank P, Just T, Kerr J A, Pilling M J, Troe J, Walker R W and Warnatz J 1992 J. Phys. Chem. Ref. Data 21411

54. Du H and Hessler J P 1992 J. Chem. Phys. 961077

55. Hidaka Y, Nakamura T, Tanaka H, Jinno A and Kawano H 1992 Int. J. Chem. Kinet. 24761

56. Skinner G B and Ruehrwein R A 1959 J. Phys. Chem 63 1736

57. Blackmore D R and Hinshelwood C 1963 Proc. R. Soc. London A 27134

58. Knyazev V D, Bencsura A, Stoliarov S I and Slagle I R 1996 J. Phys. Chem. 10011346

59. Lim K P and Michael J V 1994 Symp. Int. Combust. Proc. 25713

60. Sivaramakrishnan R, Su M C, Michael J V, Klippenstein S J, Harding L B and Ruscic B 2011 J. Phys. Chem. A 1153366

61. Tsang W and Hampson R F 1986 J. Phys. Chem. Ref. Data 151087

62. Markus M W, Woiki D and Roth P 1992 Symp. Int. Combust. Proc. 24581

63. Sutherland J W, Su M C and Michael J V 2001 Int. J. Chem. Kinet. 33669

64. Zhang H X and Back M H 1990 Int. J. Chem. Kinet. 2221

65. Tsang W, Cui J P and Walker J A 1990 Proceedings of the 17th International Symposium on Shock Waves \& Shock Tubes American Institute of Physics (New York) p. 63

66. Loser U, Scherzer K and Weber K 1989 Z. Phys. Chem. 270237

67. Curran H J 2006 Int. J. Chem. Kinet. 38250

68. Konar R S, Marshall R M and Purnell J H 1968 Trans. Faraday Soc. 64405

69. Tsang W 1988 J. Phys. Chem. Ref. Data 17887

70. Zheng X B and Blowers P 2006 Ind. Eng. Chem. Res. 45 530

71. Tsang W 1991 J. Phys. Chem. Ref. Data 20221 